Article

\title{
Loss of Polycomb Repressive Complex 2 Function Alters Digestive Organ Homeostasis and Neuronal Differentiation in Zebrafish
}

\author{
Ludivine Raby ${ }^{1,+}$, Pamela Völkel ${ }^{1,+}+\mathbb{D}$, Shaghayegh Hasanpour ${ }^{2}$, Julien Cicero ${ }^{1,3}{ }^{-\infty}$, Robert-Alain Toillon ${ }^{1}$, \\ Eric Adriaenssens ${ }^{1}$, Isabelle Van Seuningen ${ }^{1} \mathbb{( \mathbb { D }}$, Xuefen Le Bourhis ${ }^{1}(\mathbb{D})$ and Pierre-Olivier Angrand ${ }^{1, *(\mathbb{D})}$
}

1 Univ. Lille, CNRS, Inserm, CHU Lille, UMR 9020-U 1277 - CANTHER - Cancer Heterogeneity Plasticity and Resistance to Therapies, F-59000 Lille, France; ludivine.raby.etu@univ-lille.fr (L.R.); pamela.voelkel@univ-lille.fr (P.V.); julien.cicero.etu@univ-lille.fr (J.C.); robert-alain.toillon@univ-lille.fr (R.-A.T.); eric.adriaenssens@univ-lille.fr (E.A.); isabelle.vanseuningen@inserm.fr (I.V.S.); xuefen.le-bourhis@univ-lille.fr (X.L.B.)

2 Department of Fisheries and Animal Sciences, Faculty of Natural Resources, University of Tehran, Karaj 31587-77871, Iran; shaghayegh.hasanpour88@yahoo.com

3 Univ. Artois, UR 2465, Laboratoire de la Barrière Hémato-Encéphalique (LBHE), F-62300 Lens, France

* Correspondence: pierre-olivier.angrand@univ-lille.fr; Tel.: +33-3-2033-6222

+ These authors contributed equally to the work.

Citation: Raby, L.; Völkel, P.; Hasanpour, S.; Cicero, J.; Toillon, R.-A.; Adriaenssens, E.; Van Seuningen, I.; Le Bourhis, X.; Angrand, P.-O. Loss of Polycomb Repressive Complex 2 Function Alters Digestive Organ Homeostasis and Neuronal Differentiation in Zebrafish. Cells 2021, 10, 3142. https://doi.org/10.3390/cells 10113142

Academic Editor: Edor Kabashi

Received: 12 October 2021

Accepted: 9 November 2021

Published: 12 November 2021

Publisher's Note: MDPI stays neutral with regard to jurisdictional claims in published maps and institutional affiliations.

Copyright: (c) 2021 by the authors. Licensee MDPI, Basel, Switzerland. This article is an open access article distributed under the terms and conditions of the Creative Commons Attribution (CC BY) license (https:// creativecommons.org/licenses/by/ $4.0 /)$.

\begin{abstract}
Polycomb repressive complex 2 (PRC2) mediates histone H3K27me3 methylation and the stable transcriptional repression of a number of gene expression programs involved in the control of cellular identity during development and differentiation. Here, we report on the generation and on the characterization of a zebrafish line harboring a null allele of eed, a gene coding for an essential component of the PRC2. Homozygous eed-deficient mutants present a normal body plan development but display strong defects at the level of the digestive organs, such as reduced size of the pancreas, hepatic steatosis, and a loss of the intestinal structures, to die finally at around 10-12 days post fertilization. In addition, we found that PRC2 loss of function impairs neuronal differentiation in very specific and discrete areas of the brain and increases larval activity in locomotor assays. Our work highlights that zebrafish is a suited model to study human pathologies associated with PRC2 loss of function and H3K27me3 decrease.
\end{abstract}

Keywords: zebrafish; epigenetics; PRC2; EED; polycomb repression

\section{Introduction}

Polycomb group (PcG) proteins are epigenetic repressors involved in a variety of biological processes, including stem cell renewal and control of cell identity during differentiation and development [1-3]. PcG proteins associate into two main histone-modifying protein complexes named polycomb repressive complexes 1 and 2 (PRC1 and PRC2) [4-6]. According to the current canonical model, PRC2 mono-, di-, and trimethylates lysine 27 of histone H3 (H3K27me1/2/3) [7-9] leading to the recruitment of PRC1 that in turn monoubiquitinylates lysine 119 of histone H2A (H2AK119ub) [10,11]. These histone modifications induce chromatin compaction and transcriptional silencing at numerous PRC2target gene expression programs involved in cell fate, cell differentiation, lineage specification, or development [12-19]. Thus, PRC2 that initiates polycomb repression appears central to epigenetic regulation. The PRC2 core complex consists of four stoichiometric factors EZH2 or EZH1, SUZ12, EED, and RBBP4/7. The first three proteins, EZH1/2, SUZ12, and EED, form the minimal complex possessing the histone methyltransferase activity. EZH2 and EZH1 are two mutually exclusive paralogs harboring the catalytic activity, but EZH2 appears to be the main catalytic subunit of PRC2 during development and remains more efficient than EZH1 at methylating H3K27 [20]. However, the catalytic 
activity of EZH1/2 requires the physical association with EED and SUZ12 as their absence inhibits PRC2 activity. RBBP4/7 is required for PRC2 binding to nucleosomes and enhances its methyltransferase activity. In addition, a number of facultative subunits have been reported to bind to the PRC2 core complex at a substoichiometric level defining at least two distinct multimeric complexes, PRC2.1 and PRC2.2. PRC2.1 contains one of the PCL proteins (PHF1, MTF2, or PHF19), together with EPOP or PALI1, whereas PRC2.2 is associated with AEBP2 and JARID2. These additional proteins are involved in PRC2 recruitment to chromatin, stabilization of the protein complex, and/or modulation of its activity [5,21-23]. In this landscape, SUZ12 and EED are the only two components associated with all PRC2 alternate protein complexes and are absolutely required for deposition and spreading of the H3K27me2/3 epigenetic marks into the epigenome. Indeed, these components are essential for early mouse development, and mice lacking Suz12 or Eed functions are not viable and die during early postimplantation stages [24,25]. In humans, EED mutations and variants have been identified in different pathologies, including cancers [26-29] as well as abnormal developmental syndromes [30-34].

Here, we describe the use of the zebrafish model to investigate the function of Eed. Zebrafish (Danio rerio) is a widely used vertebrate model for studying gene functions in development, morphogenesis as well as in physiopathological conditions. Furthermore, this organism is particularly suited to study the role of the PRC2 complex and H3K27me3 methylation. Indeed, it has been previously shown that in contrast to mice, loss of function of several core subunits of the PRC2 complex, including Ezh1 [35,36], Ezh2 [37,38], and Suz12a/b [39], does not lead to zebrafish lethality at gastrulation. Instead, ezh2 and suz12a; suz12b homozygous mutants die at around 12 days post fertilization (dpf), after body plan formation and tissue specification [37-39], whereas ezh1 homozygous mutants are viable and fertile [35,36]. This absence of embryonic lethality in zebrafish allows the study of the role of H3K27me3 methylation in tissue development and homeostasis without the requirement of conditional knockout strategies. In this study, we generated and characterized null alleles of eed to investigate the role of PRC2 function and H3K27me2/3 methylation in zebrafish development and organogenesis. Homozygous eed ${ }^{-/-}$mutants die at around 10-12 dpf with strong defects at the level of the digestive organs, including reduced size of the pancreas, hepatic steatosis, and loss of the intestinal structures. However, this relatively late lethality allowed us to focus on the expression of markers of the developmental brain. We found that PRC2 loss of function alters neuronal differentiation in very specific and discrete areas of the brain. Furthermore, locomotor activity assays highlighted the role of PRC2 in the zebrafish larval behavior. Altogether, our observations showed that this eed-deficient zebrafish line could constitute a valuable model to study the impact of H3K27me3 decrease and PRC2 loss of function in development as well as in several human pathologies.

\section{Materials and Methods}

\subsection{Zebrafish Maintenance, Embryo Preparation, and Animal Ethics Statements}

Zebrafish from the TU strain and Tg(actb2:GFP-Hsa.UTRN) ${ }^{\mathrm{e} 116}$ transgenics [40] are maintained at $27.5^{\circ} \mathrm{C}$ in a $14 / 10 \mathrm{~h}$ light/dark cycle. The evening before spawning, males and females were separated into individual breeding tanks (Tecniplast, Decines-Charpieu, France). Spontaneous spawning occurred the following morning when the plastic divider was removed. Embryos were collected and staged according to Kimmel et al. [41]. The chorions were removed from embryos using 1\% pronase (Sigma, St. Louis, MO, USA) for $1 \mathrm{~min}$. Zebrafish embryos were fixed overnight in $4 \%$ paraformaldehyde in PBS (phosphatebuffered saline), dehydrated gradually to $100 \%$ methanol, and stored at $-20{ }^{\circ} \mathrm{C}$.

Zebrafish were maintained in compliance with the French and European Union guidelines for the handling of laboratory animals (Directive 2010/63/EU of the European Parliament and of the Council of 22 September 2010 on the protection of animals used for scientific purposes). The experimental procedures carried out on zebrafish were reviewed and approved by the local Ethics Committee, CEEA 75 Nord Pas-de-Calais, and the 
French Ministry of Higher Education and Research (APAFiS approval number 135272018011722529804_v3).

\subsection{TALEN Design and Assembly}

TALENs targeting eed were designed and assembled as previously described [42]. The eed TALEN target site was selected using the online TAL Effector-Nucleotide Targeter tool (https: / / tale-nt.cac.cornell.edu/, last accessed on 11 October 2021 [43]) in exon 3 (ENSDART00000162928.1) with the presence of a restriction site (BseNI) within the spacer sequence for screening and genotyping purposes.

Eed-specific TALEN constructs were engineered using the TALEN Golden Gate assembly system described by Cermak et al. [44] using the expression backbones, pCS2TAL3DD and pCS2TAL3RR [45]. Plasmids for Golden Gate Cloning were obtained from Addgene.

\section{3. mRNA Injection into Zebrafish Embryos}

Capped mRNAs were synthetized using SP6 mMESSAGE mMACHINE kit (Ambion) from linearized plasmid templates. mRNAs (50-100 pg) were injected into 1-cell zebrafish embryos using a FemtoJet microinjector (Eppendorf, Matesson, France).

\subsection{Genotype Analyses}

For genotyping, embryos, larvae or caudal biopsies of larvae were incubated in $10 \mu \mathrm{L}$ PCR extraction buffer (10 mM Tris-HCl pH 8.0, 2 mM EDTA, 0.2\% Triton X-100, $100 \mu \mathrm{g} / \mathrm{mL}$ proteinase $\mathrm{K}$ ) and placed at $50{ }^{\circ} \mathrm{C}$ for $4 \mathrm{~h}$ prior to proteinase $\mathrm{K}$ inactivation at $95{ }^{\circ} \mathrm{C}$ for $5 \mathrm{~min}$. Genotype analysis was performed by PCR on $2.5 \mu \mathrm{L}$ of samples using the primer set TAL_eed_5' (CAGCCTAAAGGTGAGGCCGC) and TAL_eed_3'a (CGATCTCGACCCGGAACAC) followed by PCR product digestion with the BseNI restriction enzyme. An alternate genotyping strategy consists of the PCR amplification of genomic DNAs with the primer set TAL_eed5_new GTGTGCAGGAGGATCATGGTCAG) and TAL_eed3_new (GTCCGTCACTCACTCTGTTGCTG) followed by a $\%$ agarose gel electrophoresis without enzymatic digestion.

To genotype paraformaldehyde-fixed embryos and larvae, DNA was extracted using sodium hydroxide and Tris [46]. Single embryos or larvae were placed into microcentrifuge tubes containing $20 \mu \mathrm{L} 50 \mathrm{mM} \mathrm{NaOH}$ and heated $20 \mathrm{~min}$ at $95^{\circ} \mathrm{C}$. The tubes were then cooled to $4{ }^{\circ} \mathrm{C}$, and $2 \mu \mathrm{L}$ of $1 \mathrm{M}$ Tris- $\mathrm{HCl}, \mathrm{pH} 7.4$, was added to neutralize the basic solution. Genotype analysis was performed on $2.5 \mu \mathrm{L}$ of samples by PCR-BseNI digestion or PCR without digestion, as described above.

Sequence determination (GATC-Eurofin, Ebersberg, Germany) was performed after cloning of the PCR products into pCR-XL-TOPO (Invitrogen-ThermoFisher, Waltham, MA, USA) according to the manufacturer's instructions.

\subsection{Kaplan-Meier Analysis}

For the establishment of survival curves, the tip of the caudal fin of embryos from an $\mathrm{eed}^{+/-}$incross was transected within the pigment gap distal to the circulating blood for genotyping purposes [46]. The embryos were then pooled according to their genotypes, placed into separate 1-L tanks, and incubated at $28^{\circ} \mathrm{C}$. Larvae were fed from $5 \mathrm{dpf}$ on, 3 times per day, with early-stage zebrafish nutrition (Gemma Micro ZF75, Planktovie, France). The larvae were regularly examined directly in the tanks using a Leica EZ4 stereomicroscope with no or minimal manipulation during a period of 18 days after the spawn. Larvae were declared dead when heartbeats could not be detected. Dead larvae were immediately removed from the tanks.

\subsection{Oil Red-O Staining}

Zebrafish larvae were fixed overnight in $4 \%$ paraformaldehyde and pigments were bleached $2 \mathrm{~h}$ in $1 \% \mathrm{KOH}, 3 \% \mathrm{H}_{2} \mathrm{O}_{2}$. Larvae were stained with oil red-O (Hamiya Biomedical Company, Tukwila, WA, USA) for 15 min. Stained larvae were washed with PBS, stored in 
$70 \%$ glycerol, and imaged on a bright-field Leica MZ125 stereomicroscope equipped with a Leica DFC295 digital camera. After imaging, DNA was extracted using sodium hydroxide and Tris and genotyped.

\subsection{Smurf Assay}

Smurf assays were conducted according to Dambroise et al. [47] by placing zebrafish larvae in $50 \mathrm{~mL}$ Falcon tubes containing $2.5 \%$ blue \#1 (erioglaucine disodium salt, Sigma) for $30 \mathrm{~min}$ at room temperature. They were then rinsed under aquarium water until no more blue coloration could be found in the eluate, anesthetized in $0.016 \%$ tricaine (MS-222; 3 -amino benzoic acid ethyl ester, Sigma) and imaged on a bright-field stereomicroscope (Leica MZ125) equipped with a Leica DFC295 digital camera. After imaging, DNA was extracted for genotyping analyses.

\subsection{Histological Analysis}

For histological analyses, tail biopsies were used for genotyping before paraformaldehyde fixation of the larvae. Larvae were embedded in paraffin and cut into $5 \mu \mathrm{m}$-thick sections. These were mounted on sylanated glass slides, deparaffinated, rehydrated, and stained with hematoxylin and eosin for histological analysis as previously described [46].

\subsection{Biometric Measurements}

Standard length and eye diameter were measured according to Parichy et al. [48] on anesthetized larvae using ImageJ. After imaging and measurement, the larvae were genotyped.

Measurements of the surface of the pancreas labeled by in situ hybridization with a prss1 probe were performed by equal intensity pixel counting using ImageJ.

Quantification of macrovesicular in the liver was performed on at least 3 consecutive hematoxylin and eosin-stained slides from 4 wild-type and $4 \mathrm{eed}^{-/-}$mutant larvae using ImageJ. Each image was anonymized and transformed into an 8-bit grayscale picture before counting the hepatic nuclei and the number of vesicles.

For all biometric measurements, the software GraphPad Prism was used to build the graphs and to perform the statistical analyses.

\subsection{Confocal Microscopy}

For confocal imaging, tail biopsies were transected for genotyping before paraformaldehyde fixation of the larvae. After fixation in $4 \%$ paraformaldehyde, zebrafish larvae were maintained on glass-bottom dishes in 1.5\% agarose. Fluorescent images were captured with an LSM 880 microscope and an AiryScan detector (ZEISS, Oberkoden, Germany). A Z-stack slice was made every $5 \mu \mathrm{m}$.

\subsection{Whole-Mount In Situ Hybridization}

Antisense-RNA probes were generated by RT-PCR from total mRNA extracted from zebrafish larvae at $5 \mathrm{dpf}$ using the RNeasy Mini Kit (Qiagen, Courtaboeuf, France), following the manufacturer's protocol. After reverse transcription (Superscript III, Invitrogen), cDNAs were amplified by PCR using the probe-specific primers, coupled to the T7 sequence for forward primers and the SP6 sequence for reverse primers. DIG-labeled antisense-RNA probes were synthetized using the DIG RNA Labeling Kit (SP6) (Roche-Sigma Aldrich Chimie S.a.r.l., Saint-Quentin-Follavier, France), following the manufacturer's instructions.

The primers used for probe generation were:

ISHa_eed_F: TAATACGACTCACTATAGGG GCTGTGGCGGCTGGACTCTG ISHa_eed_R: GATTTAGGTGACACTATAG CGCCAGATGGAGGCGTCGT ISH_fabp2_F: TAATACGACTCACTATAGGG ATGACCTTCAACGGGACCTGG ISH_fabp2_R: GATTTAGGTGACACTATAG AGCCCTCTTGAAAATCCTCTTGGC ISH_ace2_F: TAATACGACTCACTATAGGGCTGTTGGAGAGATCATGTCGCTTTCT ISH_ace2_R: GATTTAGGTGACACTATAGTGTCTTCCTCAAAGGCTTTGTTCACT ISHa_fabp10a_F: TAATACGACTCACTATAGGG AAAGCATGGCCTTCAGCGGGA 
ISHa_fabp10a_R: GATTTAGGTGACACTATAG GTCAGCGTCTCCACCATTTCTCCA ISH_prss1_F: TAATACGACTCACTATAGGG TGCTCACTGCTACAAGTCCCGT ISH_prss1_R: GATTTAGGTGACACTATAG CCCGAGCTTAGTTGGAGTTCATGGT ISH_phox2bb_F: TAATACGACTCACTATAGGG GGGCCTAACCCGAACCCTACCTC ISH_phox2bb_R: GATTTAGGTGACACTATAG GAGCGCACATCGCAGTCTATCGG ISH_pcna_F: TAATACGACTCACTATAGGG GGCAACATCAAGCTCTCACA ISH_pcna_R: GATTTAGGTGACACTATAG AAATCCCACAGATGACAGGC ISH_ccna2_F: TAATACGACTCACTATAGGGGGAAGGATGTCAACACAAGGAAG ISH_ccna2_R: GATTTAGGTGACACTATAGGAGAGAACTGTCAGCACCAGATG ISH_ccnd1_F: TAATACGACTCACTATAGGGTTTGCTGCGAAGTGGATACCA ISH_ccnd1_R: GATTTAGGTGACACTATAGAACAGTTTGGGCGTGCTGAGT ISH_sox2_F: TAATACGACTCACTATAGGG GTCCGAGAGCGAGAAGCGACC ISH_sox2_R: GATTTAGGTGACACTATAGGCTGTAGGTGGGCGAGCCGT ISH_mycn_F: TAATACGACTCACTATAGGGTGCGACTCCAAACGGGAGGCA ISH_mycn_R: GATTTAGGTGACACTATAGGCTCACTTCGGGCGCTTTGACT ISH_neurod1_F: TAATACGACTCACTATAGGGTCGAGACGCTCCGACTAGCCAA ISH_neurod1_R: GATTTAGGTGACACTATAGGCGTCGAGCCCGCGTAAAGA ISH_mag_F: TAATACGACTCACTATAGGGCCGTGAGGGTGTTCAGTGTGTGT ISH_mag_R: GATTTAGGTGACACTATAGCGTCTCCCGTGCCTTCCTCT

RNA probes for bmi1 $a$ were synthesized with the DIG RNA Labeling Kit (SP6/T7) (Roche) on $1 \mu \mathrm{g}$ of linearized cDNA clone MGC:56403 IMAGE:5605189 (imaGenes GmbH, Berlin, Germany).

Whole-mount in situ hybridizations were performed according to Thisse and Thisse [49]. Briefly, the fixed embryos were rehydrated and permeabilized with $10 \mu \mathrm{g} / \mathrm{mL}$ proteinase $\mathrm{K}$ for $30 \mathrm{sec}$ (1-cell stage embryos), $10 \mathrm{~min}$ ( $24 \mathrm{hpf}$ embryos), or $30 \mathrm{~min}$ (48 hpf embryos and $5 \mathrm{dpf}$ larvae) at room temperature. Ten to 15 embryos from the TU strain of each time point, or about 50 larvae from $e^{+d^{+/}}$incrosses at $5 \mathrm{dpf}$, were hybridized with digoxigeninlabeled antisense-RNA probes at $70{ }^{\circ} \mathrm{C}$. After extensive washing, the probes were detected with anti-digoxigenin-AP Fab fragment (Roche Diagnostics, 1093274, diluted at 1:10,000), followed by staining with BCIP/NBT (5-bromo-4-chloro-3-indolyl-phosphate/nitro blue tetrazolium) alkaline phosphate substrate. The embryos were imaged using a Leica MZ10F stereomicroscope equipped with a Leica DFC295 digital camera.

\subsection{Histone Extraction and Western Blot Analysis}

Histone extraction and Western blot analyses were performed from 10 larvae as described previously [46].

Primary antibodies used were mouse anti-H3K27me3 (1:1000; ab6002, Abcam, Paris, France), rabbit anti-H3K27me2 (1:500; ab24684, Abcam), rabbit anti-H3K27me1 (1:500; ab84932, Abcam), rabbit anti-H2AK119ub (1:2000; DC27C4; Cell Signaling), rabbit antiH3K9me3 (1:1000; AB8898; Millipore-Sigma Aldrich S.a.r.l., Saint-Quentin-Follavier, France), rabbit anti-H4K20me3 (1:1000; ab9053; Abcam), rabbit anti-H3K27ac (1:1000; ab4729; Abcam) and rabbit anti-H3 (1:5000; ab1791, Abcam). The secondary antibodies were peroxidase conjugated anti-mouse antibody (1:10,000; 115-035-003, Jackson ImmunoResearch, Ely, UK) and peroxidase conjugated anti-rabbit antibody (1:10,000; 711-035-152, Jackson ImmunoResearch).

\subsection{RNA Extraction, $R T-P C R$ and $R T-q P C R$}

RNA extraction and RT-PCR experiments were conducted as previously described [50]. cDNA was synthesized using Superscript III (18080-044, Invitrogen, Carlsbad, CA, USA) following the manufacturer's instructions. A quantity of $1 \mu \mathrm{g}$ of total RNAs were used to perform the reverse transcription experiments. Primers used were:

Dr_eed_cDNA_5': GGAAACGAGATGCCGAACAA

Dr-eed_cDNA_3'a: CAGCCGGATCTCTCCCTGAG

Dr_cDNA_ube2a_F: TGACTGTTGACCCACCTTACAG 
Dr_cDNA_ube2a_R: CAAATAAAAGCAAGTAACCCCG

Dr_beta-actin_cDNA_5': CGTGACATCAAGGAGAAGCT

Dr_beta-actin_cDNA_3': ATCCACATCTGCTGGAAGGT

qPCR_fasn_5': CCAGCCATAAGAACGTCAGCCGAGA

qPCR_fasn_3': CACCTTCCCGTCACACACCTCGT

qPCR_srebf1_5': ACAGCGCGGCTAATGGCAGG

qPCR_srebf1_3': TGCCCAGGAGCCGACAGGAA

qPCR_pparg_5': GCACAGGCGCTTCAGTGTTCAG

qPCR_pparg_3': CCAGCGAGTGCGTGTCGTCC

qPCR_nr1h3_5': ACCCAGCGATTGACAGCATCACCT

qPCR_nr1h3_3': CCTGCACGTTTGGTCGGTCTGCT

PCR reactions were performed as follow: $95^{\circ} \mathrm{C} 4 \mathrm{~min},\left(95^{\circ} \mathrm{C} 45 \mathrm{~s}, 65^{\circ} \mathrm{C} 45 \mathrm{~s}, 72{ }^{\circ} \mathrm{C}\right.$ $1 \mathrm{~min}) 35$ cycles, $72{ }^{\circ} \mathrm{C} 10 \mathrm{~min}$.

The quantitative qPCR reaction was performed in triplicate using a QuantStudio 3 Real-Time System (Thermo Fisher Scientific, Waltham, MA, USA) using SYBR Green Supermix (Bio-Rad, Marne-la-Coquette, France). Relative mRNA expression of each gene was normalized to $u b e 2 a$ levels.

\subsection{Behavioral Studies}

Behavioral studies were performed on $5 \mathrm{dpf}$ larvae from eed ${ }^{+/-}$incrosses in plates that were handled minimally before placement in a Zebrabox chamber (ViewPoint Life Sciences, Lyon, France) equipped with an infrared light-emitting floor and a top-mounted infrared camera allowing video recording of the whole plate under both light and dark conditions. Larval behavior measurements were achieved using the ZebraLab software with a detection threshold set at 35 and an xmin set at 3 (ViewPoint Life Sciences, Lyon, France). After recording, the larvae were euthanized, and their genotype was determined.

The locomotor activity assays were conducted in 48-well plates. The protocol consists of a 10 min initial acclimating period in the dark, followed by six alternating 10 min light and dark phases.

Thigmotaxis assays were conducted in 24-well plates. The timeline of the thigmotaxis assay protocol consists of a 6 min acclimatization step in the light followed by a 4 min dark challenge period. The arena was divided into two areas, inner and outer, of the equivalent surface. The diameter of the inner area corresponds to the total diameter of the well divided by $\sqrt{2}$. Thigmotaxis was presented as the percentage of the total distance moved or the total time spent by each larva into the outer zone during the challenge period.

\section{Results}

3.1. eed Expression during Zebrafish Development

Human EED protein is encoded by 12 exons containing gene located on chromosome 11, upstream of the HIKESHI (heat shock protein nuclear import factor hikeshi) gene. The protein is composed of 441 amino acids and contains six WD40 domains adopting a $\beta$-propeller architecture forming multiple van der Waals interactions and hydrogen bonds with a domain located at the N-terminus of EZH2 [51]. EED is conserved across vertebrate species, both at the protein and genomic levels. In zebrafish, the eed gene is located on chromosome 1. It is organized in 12 exons positioned at the $5^{\prime}$ of the hikeshi gene, thus defining an evolutionarily conserved synteny block. The gene also codes for a 441-amino-acids-long protein sharing $91.4 \%$ identity with its human ortholog and containing six WD40 domains as well (Figure 1a). 
(a)

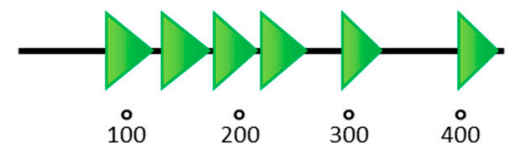

(c)

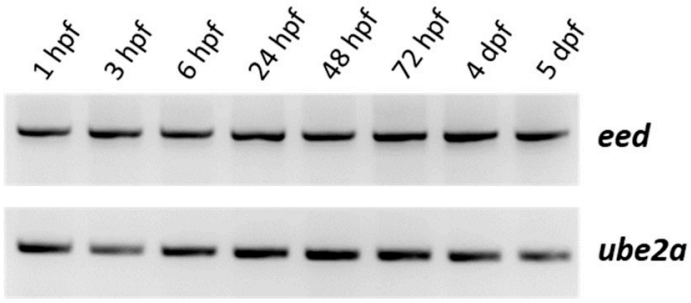

(d)

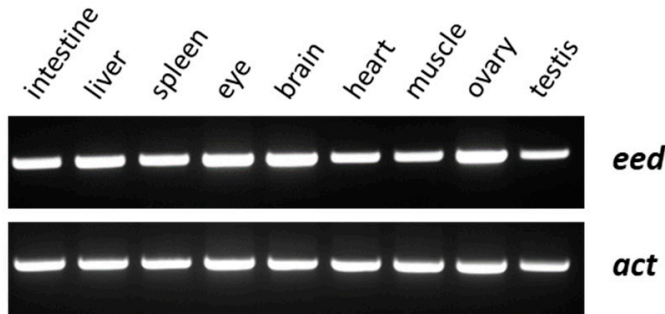

(b)

1-cell

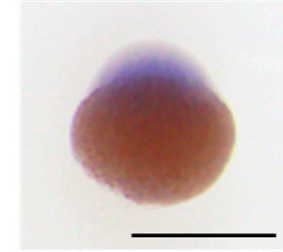

$24 \mathrm{hpf}$

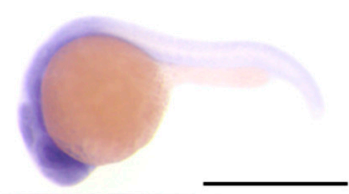

2-cell

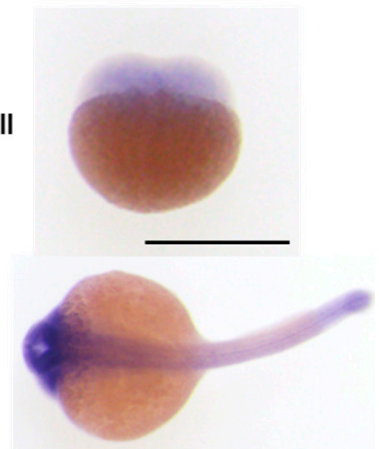

$48 \mathrm{hpf}$


$72 \mathrm{hpf}$

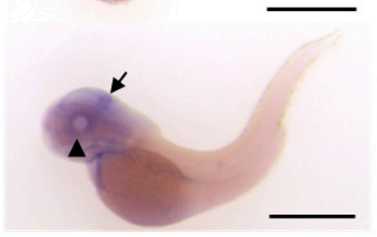

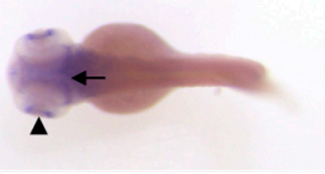

Figure 1. Organization of the Eed protein and eed mRNA expression in zebrafish: (a) schematic representation of the Eed protein. The zebrafish protein, as its human ortholog, is composed of 441 amino acids and contains six WD40 domains (SMART: SM000320) shown as green triangles; (b) whole-mount RNA in situ hybridization showing maternally provided eed transcripts at the 1-cell and 2-cell stage, and zygotic eed mRNA distribution at 24, 48 and 72 hpf. At these later stages, a lateral view is at the left and a dorsal view at the right. The arrowheads show the retina, the white asterisks the pectoral fin buds, and the arrow identify the midbrain-hindbrain boundary. Scale bar is $500 \mu \mathrm{m}$; (c) RT-PCR experiment showing the detection of eed transcripts at 1 hpf, $3 \mathrm{hpf}, 6 \mathrm{hpf}, 24 \mathrm{hpf}, 48 \mathrm{hpf}, 72 \mathrm{hpf}, 4 \mathrm{dpf}$, and $5 \mathrm{dpf}$. Ube $2 a$ is used as a control; (d) RT-PCR experiment showing eed mRNAs in adult zebrafish tissues. Beta-actin (act) is used as a control. (See Supplementary Materials).

In zebrafish, zygotic transcription is activated at about cell cycle 10-13, around $3.5 \mathrm{~h}$ post fertilization (hpf). Before this mid-blastula transition (MBT) stage, all developmental events depend on the maternally provided gene products [52,53]. Using in situ hybridization at 1-cell and 2-cell stages (Figure 1b) and RT-PCR at 1 and $3 \mathrm{hpf}$ (Figure 1c), we found in agreement with previous studies $[54,55]$ that eed mRNA is maternally loaded into the zebrafish embryo. After MBT, during tissue specification, eed zygotic expression is detected by RT-PCR (Figure 1c) and appears enriched in the anterior region of the embryo and in highly proliferative tissues such as the retina, the midbrain-hindbrain boundary, the pharyngeal arches, the pectoral fin buds or the intestine as shown by in situ hybridization at 24, 48 and $72 \mathrm{hpf}$ (Figure 1b). Finally, in adult zebrafish, RT-PCR experiments showed that eed is ubiquitously expressed in all the tissues we tested (Figure 1d).

\subsection{TALEN-Mediated Inactivation of eed in Zebrafish}

To generate eed mutations in zebrafish, we designed TALENs targeting the exon 3 within the sequence coding for the first WD40 repeat (Figure 2a). The targeted site was chosen to cover a BseNI restriction site used to screen for TALEN-induced mutations and for genotyping purposes (Figure $2 b$ ). Following TALEN mRNA injection in zebrafish embryos from the TU strain at the 1-cell stage, we isolated a line carrying an allele, eed ${ }^{u l 4}$, with a deletion of 14 base pairs (Figure 2c). This mutation produces a frameshift leading to the synthesis of a predicted protein of 136 amino acids lacking all the WD40 domains (Figure 2d). Therefore, eed ${ }^{u l 4}$ is very likely a null allele and henceforth referred to as eed ${ }^{-}$. 
(a)

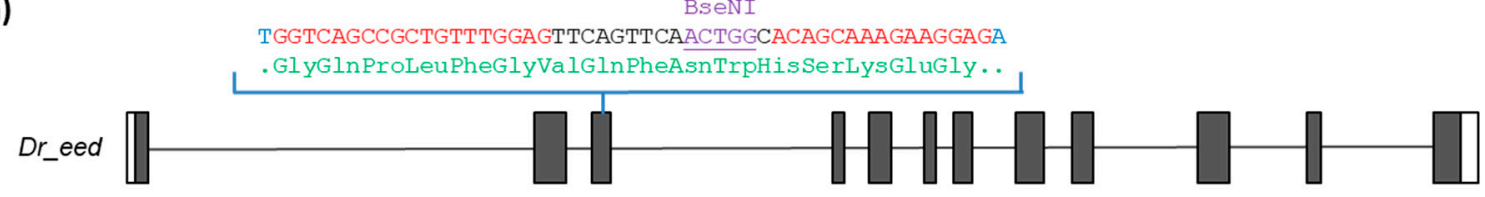

(b)

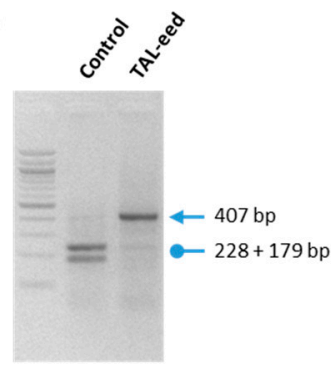

(c) TGGTCAGCCGCTGTTTGGAGTTCAGTTCAACTGGCACAGCAAAGAAGGAGA TGGTCAGCCGCTGTTTGGAGTTCAG------CAAAGAAGGAGA eed $d^{+}$ $e e d^{\text {ul4 }}$

(d)

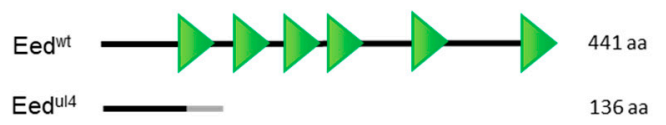

(e)

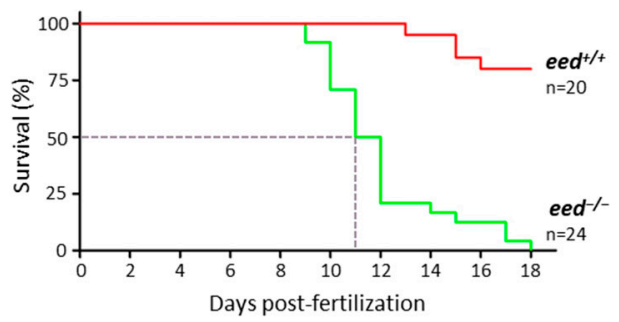

(f)

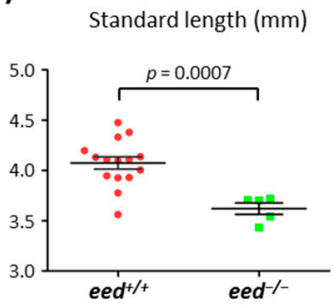

(g)

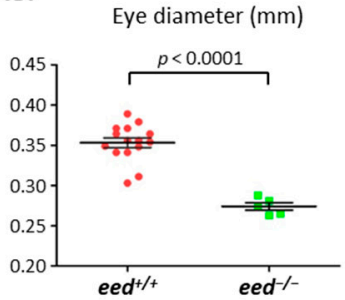

Figure 2. Loss of eed gene function leads to zebrafish death at around 10-12 dpf: (a) schematic representation of the genomic structure of the eed gene, with coding and untranslated sequences depicted as solid and open boxes, respectively. The sequence targeted by the TALEN in exon 3 is indicated with left and right TALEN binding sites shown in red, while the BseNI restriction sequence is underlined; (b) identification of mutant embryos using restriction fragment length polymorphism. Genomic DNA was prepared from an uninjected (Control) and an eed TALEN injected (TAL-eed) embryo, amplified by PCR and subjected to BseNI digestion. The TAL-eed injected embryo contains undigested material (arrow at 407 bp), indicating that the BseNI diagnostic restriction site has been disrupted; (c) sequence of the mutant allele compared to its wild-type counterpart. Dashes show deleted nucleotides. The mutated eed ${ }^{u l 4}$ allele possesses a deletion of 14 nucleotides; (d) schematic representation of wild-type $\left(\right.$ Eed $\left.^{\mathrm{wt}}\right)$ and predicted mutant $\left(\mathrm{Eed}^{\mathrm{ul}}\right)$ proteins. The gray line in the predicted mutant protein corresponds to residues read out of frame prior to encountering a premature STOP codon. The green triangles in the wild-type protein show the WD40 domains; (e) Kaplan-Meier survival curves over 18 days for $e^{+/ /+}$(red curve) and $e^{-1-}$ (green curve) siblings from a cross between heterozygous $e^{-1} d^{+-}$fish. The number of fish considered is indicated; (f) measurement of the total length of $\mathrm{eed}^{+/+}$(red) and $e e d^{-/-}$(green) siblings from a cross between heterozygous $\mathrm{eed}^{+/-}$fish at $11 \mathrm{dpf}$. Statistical significance was assessed using a t-test; (g) measurement of the eye diameter of $e e d^{+/+}$(red) and $e e d^{-/-}$(green) siblings from a cross between heterozygous $e e d^{+/-}$fish at $11 \mathrm{dpf}$. Statistical significance was assessed using a Student $t$-test.

Adult heterozygous $\mathrm{eed}^{+/-}$fish are viable, fertile, and do not show any obvious phenotype. In contrast, and similarly to $e z h 2^{-/-}[37,38]$ and suz $12 a^{-/-}$; suz $12 b^{-/-}$fish [39], homozygous eed ${ }^{-1-}$ mutants die at around 10-12 dpf (Figure 2e). Analysis of the living $e e d^{-1-}$ mutants at $11 \mathrm{dpf}$ showed that they do not present gross morphological alterations while they appear significantly smaller than wild-type siblings (Figure 2f,g). Then, eed function is not required for early development and normal formation of the body plan but is necessary for zebrafish survival after 10-12 dpf.

\subsection{Loss of eed Function Alters H3K27me2/3 Levels, but Not H3K27me1 nor H2AK119ub}

To investigate the effect of eed loss of function on histone modifications, we performed a series of Western blot analyses using antibodies recognizing specific histone marks (Figure 3). Histones were extracted from $\mathrm{eed}^{+/+}$and $\mathrm{eed} \mathrm{d}^{-/-}$siblings at $9 \mathrm{dpf}$ and subjected to Western blot analyses to determine global levels of several histone modifications. 

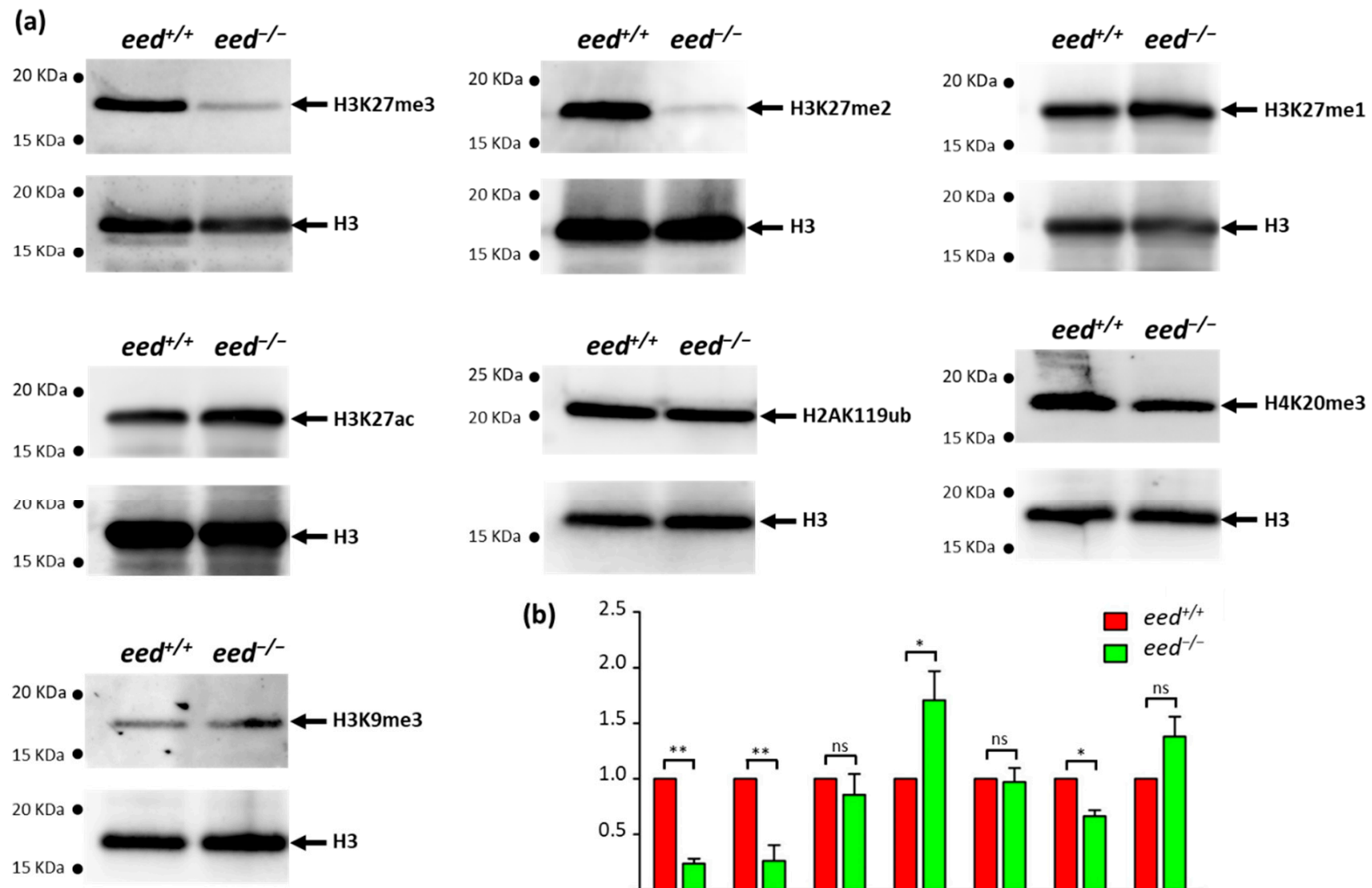

(b)

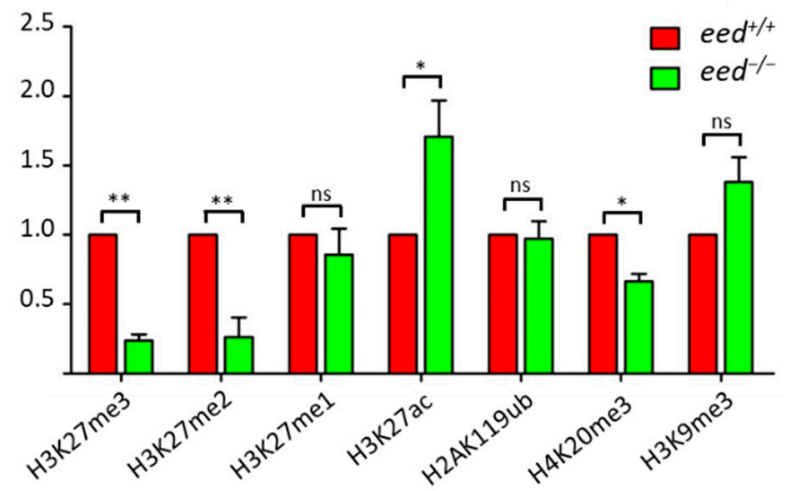

Figure 3. Effects of eed loss of function on global levels of histone modifications: (a) after genotyping of the caudal extremity of larvae, 10 to $15 \mu \mathrm{g}$ of bulk histones from a pool of $10 \mathrm{eed}^{+/+}$or eed $\mathrm{e}^{-/-}$siblings at $9 \mathrm{dpf}$ were analyzed by Western blot using specific antibodies recognizing H3K27me3, H3K27me2, H3K27me1, H2AK119ub, H3K27ac, H3K9me3 or H4K20me3. After stripping, the membranes were reprobed with an anti-histone $\mathrm{H} 3$ as a control; (b) comparison between eed ${ }^{+/+}$(red) and $e^{-1-}$ (green) siblings, of histone modification signals normalized by total histone H3 and expressed relative to the levels found in the wild-type fish. Quantified levels are the mean \pm SD of at least three independent histone extractions, except for $\mathrm{H} 3 \mathrm{~K} 9 \mathrm{me}$, where two histone extraction were performed, followed by Western blot analysis. Statistical significance was assessed using a Student $t$-test; ns, non-significant; ${ }^{*}, p<0.05 ;{ }^{* *}, p<0.01$. (See Supplementary Materials).

Not surprisingly, a great reduction in bulk H3K27me3 and H3K27me2 levels is observed in eed ${ }^{-1-}$ homozygous larvae at $9 \mathrm{dpf}$. However, faint signals for H3K27me2/3 methylations are still detected in homozygous mutant fish, presumably due to the activity of the maternal products initially deposited in the embryos. In contrast, we did not find significant differences in H3K27me1 levels between wild-type and mutant larvae. This puzzling observation might suggest that in the absence of PRC2 activity, other histone lysine methyltransferases could monomethylate H3K27 and compensate for PRC2 loss of activity. Because mammalian G9a (EHMT2) and Glp (EHMT1) histone lysine methyltransferases have been shown to target H3K27 in vivo [56,57], their zebrafish orthologs (Ehmt1a, Ehmt1b, and Ehmt2) are potential candidates that could maintain H3K27me1 levels in the absence of PRC2 function. In agreement with other studies using knockout embryonic stem cells (ESCs) and in pathological situations where the loss of H3K27me2/3 correlates with increased acetylation at H3K27 [58,59], we also found that eed ${ }^{-/-}$homozygous larvae display a slight increase in global H3K27ac levels at $9 \mathrm{dpf}$ (Figure 3).

Monoubiquitylation of H2AK119 contributes to polycomb repression and is achieved by the action of the catalytic subunits RING1/RNF2 of PRC1 [10,11]. PRC1 complexes 
consist of a variety of protein assemblies with diverse compositions and are classified as canonical (cPRC1) and non-canonical (ncPRC1) complexes [60,61]. This classification is mainly based on the presence of a chromobox (CBX) protein in cPRC1 complexes and YY1-binding protein (RYBP), or its homolog YAF2, in ncPRC1 complexes. Whereas cPRC1 is recruited to $\mathrm{H} 3 \mathrm{~K} 27 \mathrm{me} 3$ via its $\mathrm{CBX}$ subunit, ncPRC1 complexes mediate $\mathrm{H} 2 \mathrm{~A}$ ubiquitylation at polycomb target sites independently of PRC2 action and of the presence of H3K27me3 epigenetic marks [60-62]. The examination of bulk H2AK119ub did not show differences between $e e d^{-/-}$and $e e d^{+/+}$homozygous larvae at $9 \mathrm{dpf}$, indicating that in the absence of PRC2 function, ncPRC1 complexes are able to maintain normal levels of H2AK119ub (Figure 3).

Finally, to check whether an increase in the heterochromatin marks H3K9me3 and H4K20me3 could compensate for the decrease in H3K27me2/3, we investigated their relative abundance in $\mathrm{eed}^{-1-}$ homozygous mutant larvae at $9 \mathrm{dpf}$, compared to wild-type. If a decrease in H4K20me3 levels could be found in PRC2-deficient fish, we were not able to detect significant differences in bulk H3K9me3 (Figure 3). Then, the normal formation of the body plan in eed ${ }^{-/}$mutants cannot be explained by the compensation of H3K27me2/3 loss through the increase in other repressive marks.

\subsection{Loss of eed Function Alters the Homeostasis of Digestive Organs in Zebrafish}

Because it has been shown that ezh2-deficient zebrafish develop intestinal defects [38,63], we investigated the potential effect of eed loss of function on the development of digestive organs. First, we examined the expression of markers of the intestine (fabp2, fatty acidbinding protein 2, intestinal and ace2, angiotensin I converting enzyme 2), the liver (fabp10a, fatty acid-binding protein 10a, liver basic), and the exocrine pancreas (prss1, serine protease 1 also known as trypsin, try) in 5-dpf old larvae by in situ hybridization (Figure 4a). Pools of larvae from heterozygous eed $\mathrm{e}^{+/-}$incrosses were subjected to in situ hybridization and individually pictured before being genotyped by RFLP.

(a)

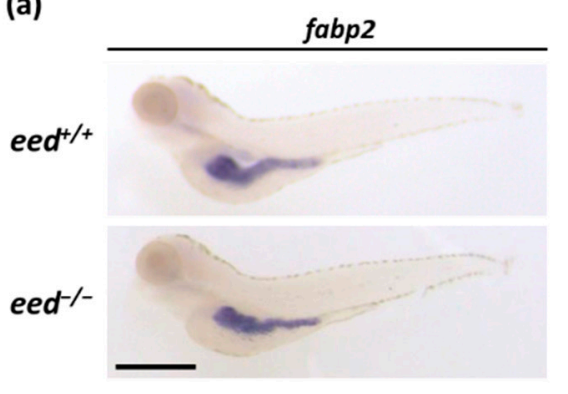

fabp10a

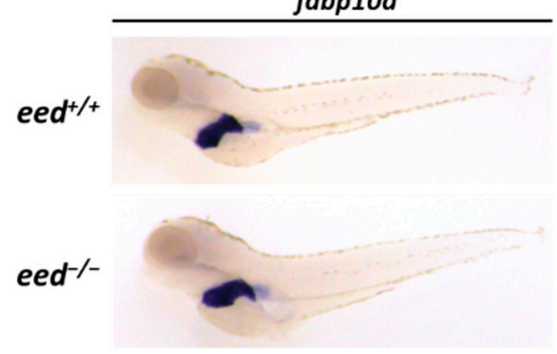

ace2

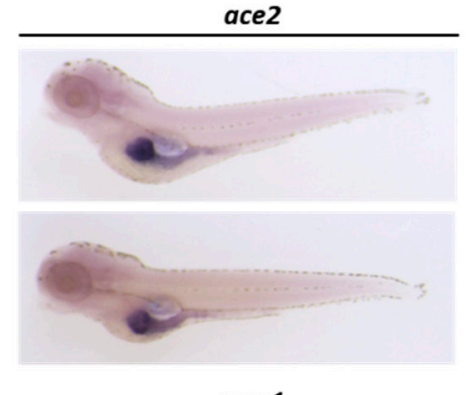

prss1

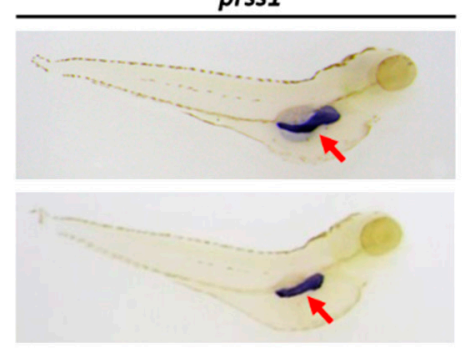

(b)

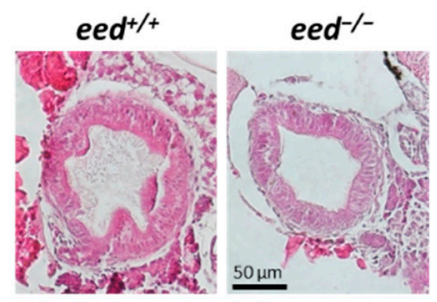

(c)

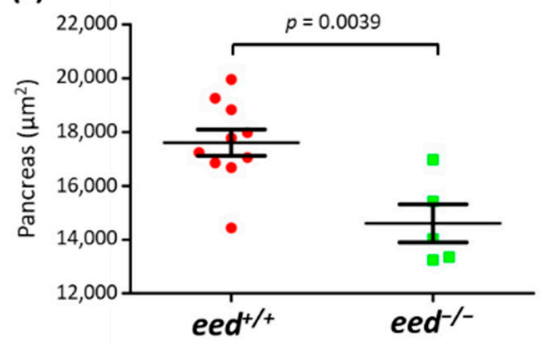

Figure 4. Organization of the digestive organs at $5 \mathrm{dpf}$ : (a) whole-mount RNA in situ hybridization to detect the expression of markers of the intestine (fabp2, ace2), the liver (fapb10a), and the exocrine pancreas (prss1) in eed ${ }^{+/+}$and eed $d^{-/-}$siblings at $5 \mathrm{dpf}$. The red arrow shows the pancreas. Scale bar is $500 \mu \mathrm{m} ;(\mathbf{b})$ intestinal bulb sections from eed $d^{+/+}$(left) and eed ${ }^{-/-}$(right) larvae at $5 \mathrm{dpf}$ stained with hematoxylin and eosin. Scale bar is $50 \mu \mathrm{m}$; (c) measurement of the surface of the pancreas labeled by in situ hybridization using a prss1 probe at $5 \mathrm{dpf}$ for $e e d^{+/+}$(red) and $e \mathrm{~d}^{-/-}$(green) larvae. Statistical significance was assessed by a Student t-test, and the corresponding $p$-value is indicated. 
The expression of $f a b p 2, a c e 2$, and fabp $10 a$ revealed that the intestine and the liver are normally developed in eed ${ }^{-/-}$larvae at $5 \mathrm{dpf}$. Furthermore, histological studies showed that the structure of the intestine is identical in eed $d^{+/+}$and eed ${ }^{-/-}$zebrafish at this stage (Figure $4 b$ ). In contrast, and similar to what was observed in $e z h 2^{-/-}$mutants [38], the size of the pancreas appears smaller in eed-deficient fish at $5 \mathrm{dpf}$ (Figure $4 \mathrm{a}, \mathrm{c}$ ).

To visualize the intestine structure in the whole larvae at a later developmental stage by confocal microscopy, we used the transgenic line $\mathrm{Tg}$ (actb2:GFP-Hsa.UTRN) ${ }^{\mathrm{e} 116}$ in which actin is labeled by the green fluorescent protein (GFP) $[40,64,65]$. Fluorescence imaging revealed an alteration of the intestine structure of the eed ${ }^{-1-}$ transgenics at $9 \mathrm{dpf}$. Indeed, the number of cells forming the thickness of the intestinal wall and visible through GFP expression is decreased in eed-deficient zebrafish as of $9 \mathrm{dpf}$ (Figure 5a). Then, while the intestine develops normally until $5 \mathrm{dpf}$, its integrity fails to be maintained at later developmental stages.

(a)
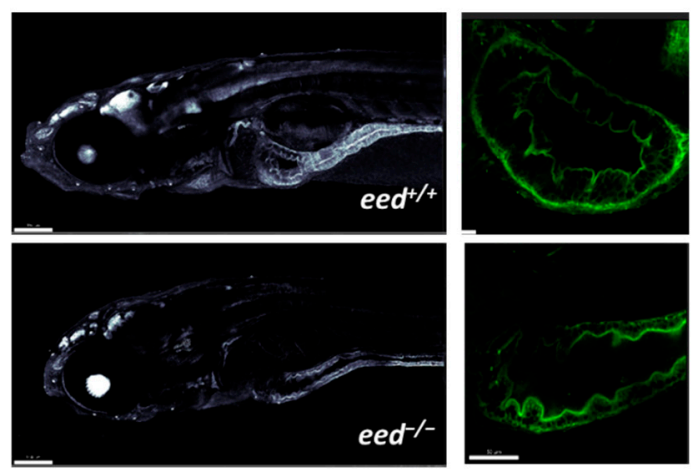

(c)



(b)
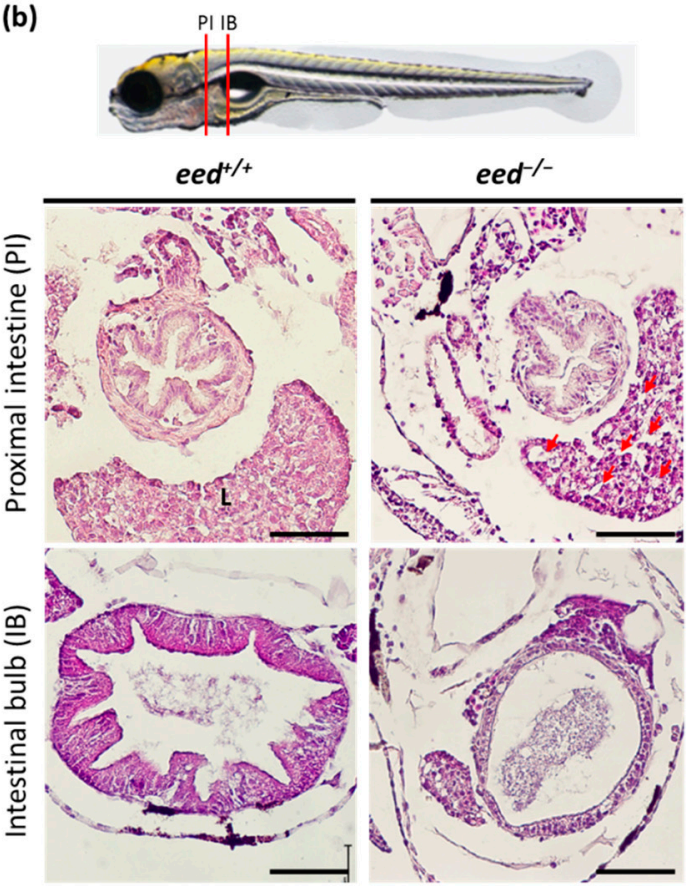

Figure 5. Structure of the intestine at 9-11 dpf: (a). confocal imaging of the anterior part (left, scale bar is $150 \mu \mathrm{m}$ ) and of the intestine bulb (right, scale bar is $50 \mu \mathrm{m}$ ) of transgenic $\mathrm{Tg}$ (actb2:GFP-Hsa.UTRN) ${ }^{\mathrm{e} 116}$ zebrafish larvae, wild-type (up) or lacking eed function (down) at $9 \mathrm{dpf}$ (b) histological sections stained with hematoxylin and eosin at the levels of the proximal intestine (PI) and the intestinal bulb (IB) as indicated from eed ${ }^{+/+}$(left) and eed ${ }^{-/-}$(right) siblings at $11 \mathrm{dpf}$. Red arrows show macrovesicles. L, liver. Scale bar is $50 \mu \mathrm{m}$; (c) Smurf assay performed on eed ${ }^{+/+}$and eed ${ }^{-/-}$siblings at $11 \mathrm{dpf}$. Scale bar is $200 \mu \mathrm{m}$.

The analysis of histological sections of larvae at $11 \mathrm{dpf}$ confirmed that the intestine wall of eed $\mathrm{e}^{-/-}$mutants is strongly reduced and lacks folds at the level of the intestinal bulb (Figure 5b). By contrast, the structure of the proximal intestine does not show these strong defects, as previously observed in $e z h 2^{-/-}$mutants [38]. Because the intestine looks normal at $5 \mathrm{dpf}$ but altered at 9-11 dpf, we conclude that in the absence of eed and PRC2 functions, the development of the intestine occurs, but the integrity of its structure is not maintained. To investigate the permeability of the intestine in mutants, we performed a Smurf assay [47]. In this assay, the permeability of the intestine was assessed by evaluating the diffusion throughout the body of blue food dye present in the fish water. Figure $5 c$ shows that in spite of a strong alteration of the structure of the intestine bulb, the intestinal permeability is not increased.

Neutral lipid dye oil red-O staining of larval zebrafish is commonly used to examine steatosis caused by consumption of a high-fat diet or induced by various drugs [66-70]. Oil 
red-O staining clearly shows a strong accumulation of neutral lipids in the liver of eed ${ }^{-/-}$ larvae à $11 \mathrm{dpf}$ when compared to wild-type larvae (Figure 6a). Such a strong oil red-O staining of the liver was also found in $e z h 2^{-/-}$homozygous mutants [38], whereas exposure to Ezh1/2 inhibitor PF-06726304 acetate increases lipid accumulation in larval zebrafish [71]. Moreover, hematoxylin and eosin stain on histological sections of zebrafish larvae at $11 \mathrm{dpf}$ showed signs of macrovesicular steatosis in $e e d^{-1-}$ larvae (Figures $5 \mathrm{~b}$ and $6 \mathrm{~b}, \mathrm{c}$ ).

(a)

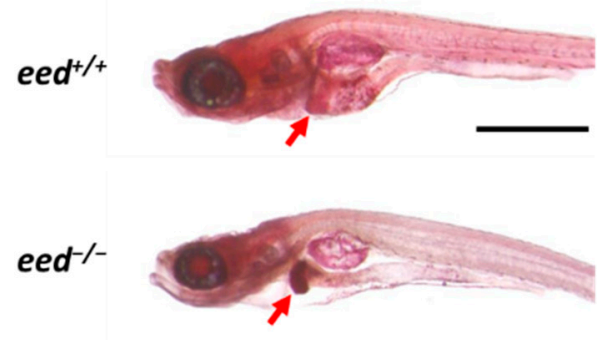

(c)

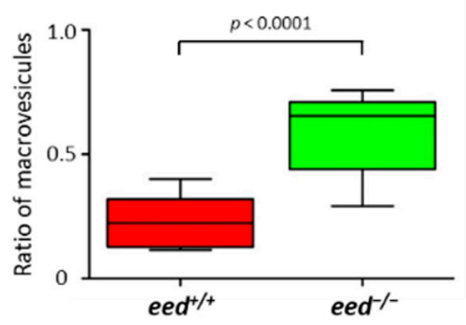

(b)

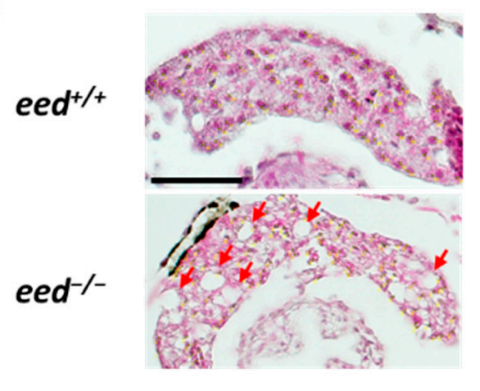

(d)

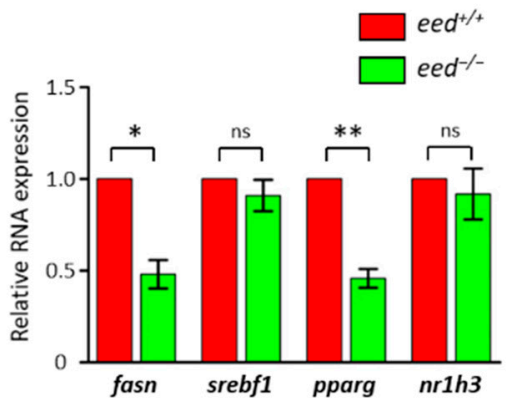

Figure 6. Liver alterations in eed-deficient larvae: (a) representative images of lateral views of $e e d^{+/+}$ and eed ${ }^{-/-}$larvae stained with oil red-O at $11 \mathrm{dpf}$. The red arrow shows the liver. Scale bar is $500 \mu \mathrm{m}$; (b) histological sections stained with hematoxylin and eosin showing the liver of $e e d^{+/+}$and $e^{e} d^{-/-}$larvae at $11 \mathrm{dpf}$. Red arrows show macrovesicles. Scale bar is $50 \mu \mathrm{m}$; (c) quantification of macrovesicular steatosis eed $\mathrm{d}^{+/+}$(red) and $e e d^{-/-}$(green) larvae at $11 \mathrm{dpf}$. The ratio of macrovesicular structures relative to total hepatic surface was calculated on 3 histological slices per larvae from 4 different larvae per genotype. Statistical significance was assessed using a Mann-Whitney $t$-test; (d) relative levels of fasn, srebf1, pparg, and nr1h3 RNA abundances in $9 \mathrm{dpf}$ old eed ${ }^{+/+}$(red) and eed ${ }^{-/-}$ (green) larvae quantified by RT-qPCR. Three independent experiments were performed, and error bars represent standard deviation. Statistical analysis was performed using a one-way ANOVA test followed by a Dunn's multiple test comparison; ns, non-significant; ${ }^{*}, p<0.05 ;{ }^{* *}, p<0.01$.

To investigate the impact of eed loss of function on the expression of lipogenic factors, we performed RT-qPCRs to determine RNA abundance for fasn (fatty acid synthetase), srebf1 (sterol regulatory element-binding transcription factor 1), pparg (peroxisome proliferator-activated receptor gamma), and nr1h3 (nuclear receptor subfamily 1, group $\mathrm{H}$, member 3 , also known as liver $\mathrm{X}$ receptor $l x r$ ) at $9 \mathrm{dpf}$. Then, in spite of showing an increase in lipid accumulation, RNA levels for lipogenic factors remain either unchanged (srebf1 and $n r 1 h 3$ ) or reduced (fasn and pparg) in eed ${ }^{-/}$larvae (Figure $6 \mathrm{~d}$ ). This suggests that eed loss of function-induced steatosis is likely the result of an increase in lipid storage in the liver rather than an increase in lipid synthesis.

Taken together, our study of eed-deficient zebrafish mutants demonstrates that PRC2 loss of function has various effects on the homeostasis of digestive organs, ranging from a delay in pancreatic development, a loss of maintenance of the intestine structures to hepatic steatosis. 


\subsection{Loss of eed Function Alters Neuronal Differentiation}

To characterize in more detail our eed-deficient zebrafish mutants, we performed additional whole-mount RNA in situ hybridization experiments at $5 \mathrm{dpf}$ with a focus on the brain. Mutant and wild-type siblings were treated in one batch for each probe and documented photographically. The genotype of each embryo was then determined by RFLP on genomic DNA extracted from the fixed and stained material. First, we showed that eed expression is strongly reduced in $e e d^{-/}$larvae, presumably due to nonsensemediated decay (NMD) of the mutant transcript (Figure 7a). Second, we investigated the expression profile of phox $2 b b$ (paired like homeobox $2 \mathrm{Bb}$ ), a transcription factor expressed by a subset of cells in the posterior regions of the brain. In eed ${ }^{-1-}$ mutants, phox $2 b b$ appears additionally expressed ectopically in the retina (Figure 7a). This phox $2 b b$ misexpression in the retina was also observed in ezh2-deficient zebrafish larvae [38]. Then, eed loss of function recapitulates the defects found in $e z h 2^{-/-}$mutants at the level of the digestive organs, but also in terms of phox $2 b b$ expression in the brain and the retina. Moreover, while eed is expressed in large territories of the brain, its loss of function impairs phox $2 b b$ specifically in the retina, indicating that $\mathrm{PRC} 2$ controls gene expression programs in a very subtle and discreet manner, depending on the cell type.

To gain insights into the possible role of PRC2 in brain development, we applied in situ hybridizations at $5 \mathrm{dpf}$ on several genes known to be expressed in the midbrain-hindbrain boundary region that contains neural stem cells and dividing progenitors [72], and where eed transcripts are abundant (Figures 1a and 7a) [54]. The genes chosen for the study were the stemness markers bmila (bmi1 polycomb ring finger oncogene 1a) and sox2 (SRY-box transcription factor 2); the proliferation marker pcna (proliferating cell nuclear antigen); mycn (MYCN proto-oncogene, bHLH transcription factor), which is involved in several signaling pathways promoting cell growth, proliferation and metabolism of progenitor cells in different developing organs and tissues; two genes coding for cyclins, ccna2 (cyclin A2) and ccnd1 (cyclin D1); neurod1 (neuronal differentiation 1), a marker of neuronal precursors; and mag (myelin-associated glycoprotein), a marker of glial precursors (Figure $7 \mathrm{~b}$ ).

Analysis of expression profiles of the stemness markers bmila and sox 2 revealed a strong increase in bmi1a labeling at the midbrain-hindbrain boundary of $e e d^{-/-}$mutants suggesting that the number of stem cells is increased, possibly due to differentiation defects in this region. In contrast, sox 2 expression seems less affected by the loss of eed function, with eventually a slight increase in sox2 RNA abundance in the hindbrain. The RNA expression profile of pcna appeared globally similar in $\mathrm{eed}^{+/+}$and $\mathrm{eed}^{-/-}$larvae indicating that PRC2 loss of function has little or no effect on cell proliferation in the developing brain at $5 \mathrm{dpf}$. However, while expression of the cyclin gene $c c n d 1$ is unchanged in eed ${ }^{-/-}$larvae, transcription of ccna2 appears in part slightly deregulated. We observed that the expression of mycn is downregulated in the hindbrain and the retina of the eed mutants. Finally, using probes for neuronal precursors (neurod1) and glial precursors (mag), whole-mount RNA in situ hybridizations showed a reduction in the labeled areas indicating that the numbers of these precursors are diminished in the hindbrain or midbrain of $e e d^{-l-}$ larvae, respectively. Altogether, our results suggest that PRC2 loss of function disturbs the differentiation and the development of a subset of neurogenic cells in the midbrain-hindbrain region and in the retina without dramatically affecting cell proliferation, as judged by pcna expression. Thus, remarkably, while eed loss of function drastically affects bmila expression, the effect of the mutation on the expression of other markers such as ccna2, mycn, neurod1, or mag remains relatively thin and affects discrete areas of the brain. 
(a)

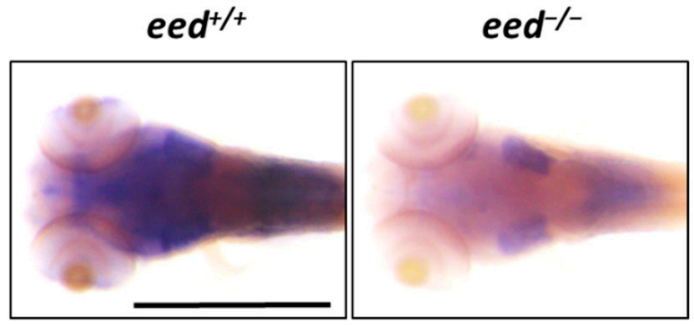

(b)



eed $^{-1-}$

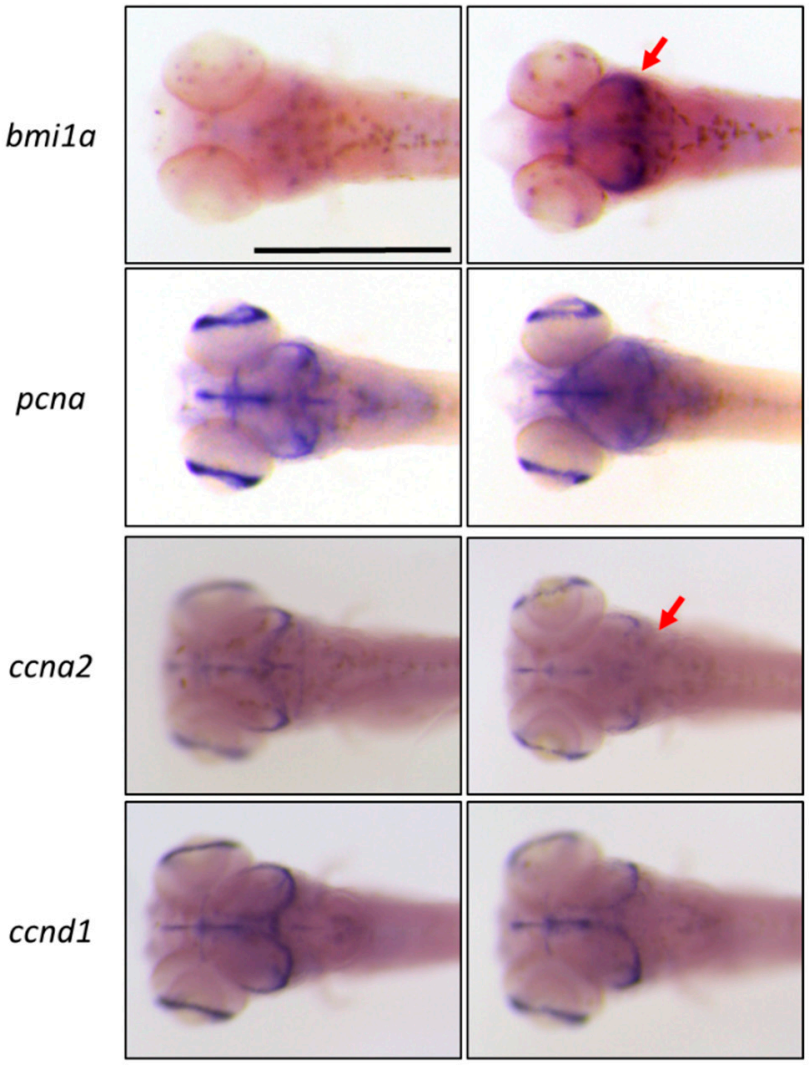

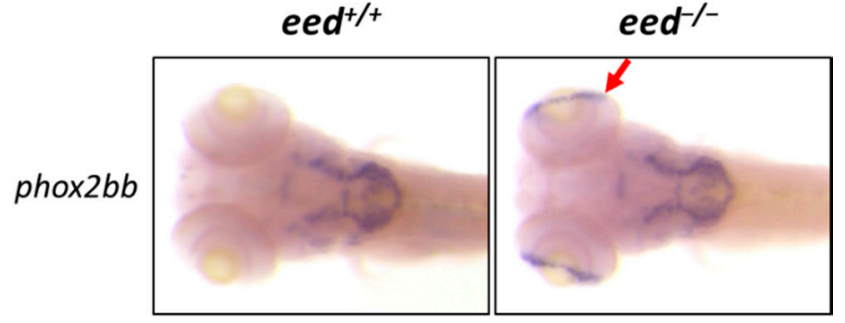

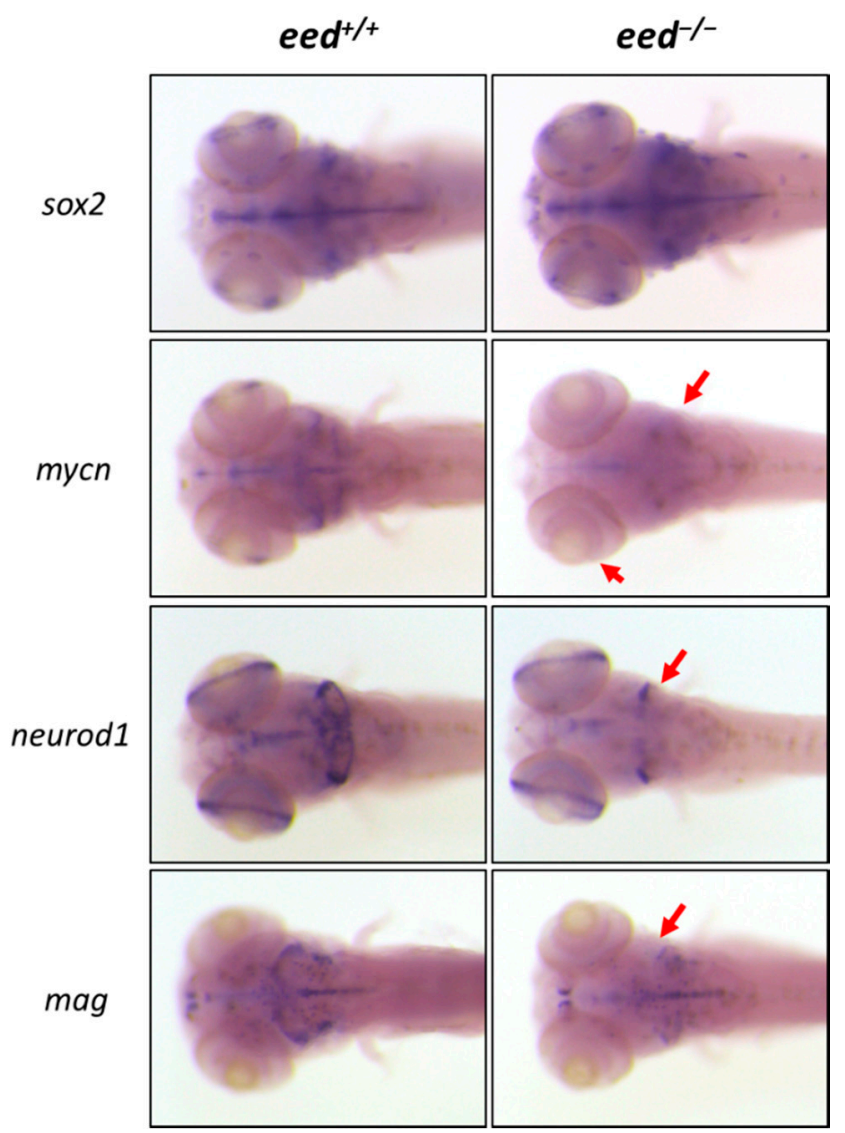

Figure 7. Whole-mount RNA in situ hybridization of the brain region of eed ${ }^{+/+}$and $e e d^{-/-}$siblings at 5 dpf: (a) whole-mount in situ hybridization to detect eed (left) and phox $2 b b$ RNA expression. The red arrow shows the phox $2 b b$ ectopic expression in the retina of eed mutants. Scale bar is $500 \mu \mathrm{m}$; (b) whole-mount in situ hybridization to detect the expression profiles of stemness (bmi1a, sox2), proliferation (pcna, mycn), cell cycle (ccna2, ccnd1), and neuronal/glial precursor (neurod1, mag) markers. The red arrows emphasize expression profile differences between $e e d^{+/+}$and $e e d^{-/-}$larvae. Scale bar is $500 \mu \mathrm{m}$.

\subsection{Loss of eed Function Alters Locomotor Activity}

Loss of eed function alters the differentiation of neurogenic cells at $5 \mathrm{dpf}$. Then, to investigate whether eed deficiency could also affect larval behavior, we performed locomotor and thigmotaxis assays. Zebrafish larvae from heterozygous $\mathrm{eed}^{+/-}$incrosses were individually disposed of into dish wells. The plates were handled minimally before placement in a Zebrabox chamber (ViewPoint Life Sciences, Lyon, France) equipped with an infrared light-emitting floor and a top-mounted infrared camera allowing video recording of the whole plate under both light and dark conditions. Larval behavior measurements were achieved using the ZebraLab software (Version 5.18.0.0, ViewPoint Life Sciences, Lyon, France). After recording, the larvae were euthanized and their genotype determined by RFLP.

The locomotor activity assays were conducted in 48-well plates following a protocol that consists of a $10 \mathrm{~min}$ initial acclimating period in the dark, followed by six alternating 
10 min light and dark phases (Figure 8a). As previously described [73], switching to light dramatically decreases larval activity, whereas return to darkness is associated with an increase in locomotor activity. Additional cycles of alternating light and dark produce alternating levels of low and high activity of the zebrafish larvae, respectively (Figure 8b). Behaviorally, eed ${ }^{-/}$larvae are hyperactive compared with wild-type larvae at $5 \mathrm{dpf}$. This hyperactive phenotype of $e e d^{-1-}$ mutant is particularly prominent and significant during the dark cycles (Figure 8b,c).

(a)

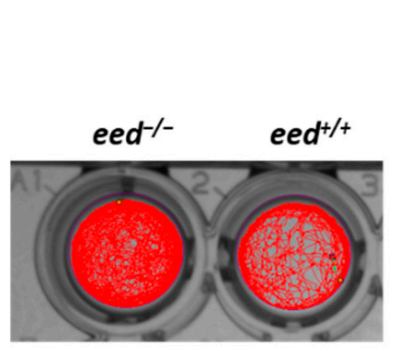

(d)

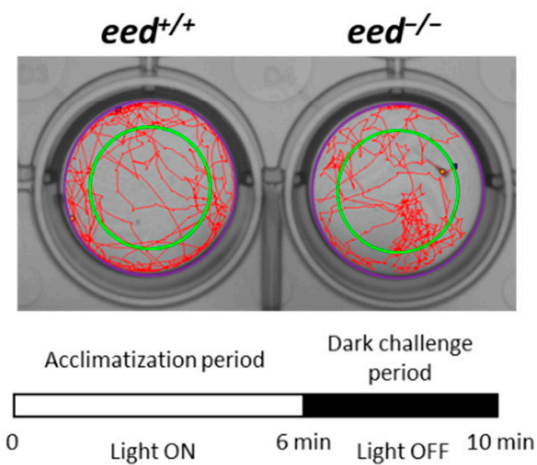

(b)



(e) (c)

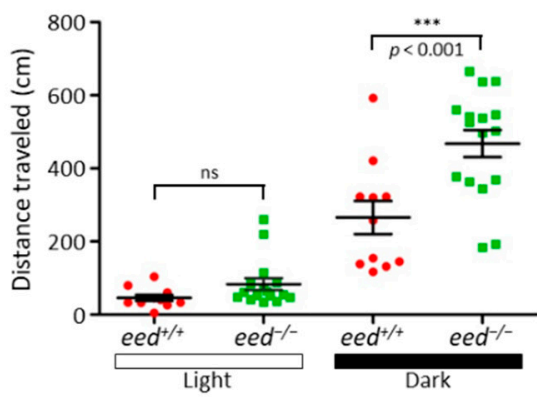

(f)

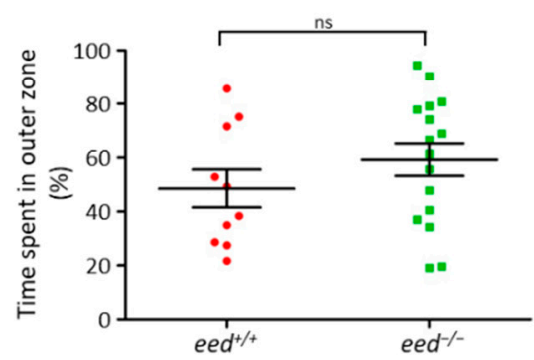

Figure 8. Behavioral comparison between wild-type and $e e d^{-/-}$mutants at $5 \mathrm{dpf}$ : (a) locomotor tracking for a 70 min recording of an eed ${ }^{-/-}$mutant (left) and a wild-type (right) larvae; (b) distance traveled throughout a 70 min session for wild-type (red, $n=11$ ) and eed ${ }^{-/-}$mutant (green, $n=16$ ). Data are presented as mean $\pm \mathrm{SD}$ of the distance moved (in $\mathrm{mm}$ ) in 2 min intervals. Black and white bars at the bottom indicate dark and light conditions, respectively. Statistical analysis was performed using two-way ANOVA followed by Bonferroni posttest comparisons; ns, non-significant; ${ }^{*}, p<0.05$; ${ }^{* *}, p<0.01 ;{ }^{* * *}, p<0.001$; (c) cumulative distance traveled for each wild-type (red) and mutant (green) larvae during the light (left) and dark (right) periods. Statistical analysis was performed using one-way ANOVA followed by Bonferroni posttest comparisons; ns, non-significant; ${ }^{* * *}, p<0.001 ;(\mathbf{d})$ the experimental procedure for the thigmotaxis assay is composed of a $6 \mathrm{~min}$ acclimatization period with the light $\mathrm{ON}$ followed by a $4 \mathrm{~min}$ visual motor challenge period with the lights OFF. Experiments are performed in a 24-well plate format. Inner and outer zones are delineated by the green circle in a way that the two zones cover equivalent spatial areas. The distance traveled during the dark challenge period is shown for two larvae; (e) cumulative distance traveled in the outer zone of wild-type (red, $n=10)$ and eed ${ }^{-/-}$mutant (green, $\left.n=16\right)$ larvae. Each point represents individual larvae. No statistical (ns) difference was found between wild-type and eed ${ }^{-/-}$mutants; $^{-16}$ (f) cumulative time spent in the outer zone of wild-type (red, $n=10$ ) and eed ${ }^{-/}$mutant (green, $\left.n=16\right)$ larvae. Each point represents unique larvae. No statistical (ns) difference was found between wild-type and eed ${ }^{-/-}$mutants.

Thigmotaxis (or "wall hugging") is a common behavioral endpoint used in preclinical studies employing rodents but also applied to the zebrafish model [74,75]. Animals engaged in thigmotaxic behavior strongly avoid the center of an arena and reduce their exploration behavior to stay or move in close proximity to the boundaries of the environ- 
ment. Thigmotaxis assays were conducted in 24-well plates using a protocol composed of a $6 \mathrm{~min}$ acclimatization period in the light followed by a $4 \mathrm{~min}$ dark challenge period. The arena was divided into two areas, inner and outer, of equivalent surface, and thigmotaxis was presented as the percentage of the total distance moved or the total time spent by each larva into the outer zone (Figure 8d). Our measurements showed that there is no significant difference in thigmotaxis behavior between $e e d^{-/-}$mutants and wild-type larvae at $5 \mathrm{dpf}$ (Figure 8e,f).

Thus, in spite of having a hyperactive phenotype, the $e e d^{-/-}$mutants do not present an increase in their exploration behavior when compared to wild-type siblings.

\section{Discussion}

PRC2 is a histone-modifying protein complex conserved from fruit flies to humans and able to deposit H3K27me1/2/3 epigenetic marks responsible in turn to local chromatin compaction and gene repression. Genome-wide studies using human or mouse embryonic stem cells showed that PRC2 and H3K27me3 marks are enriched at promoters of numerous developmental genes, leading to the proposal that PRC2 could be involved in the maintenance of the pluripotency of stem cells by keeping developmental genes repressed [12-19]. Differentiation is then associated with the relocation of the PRC2 complexes turning stem cell genes expression off and switching on gene programs specific to given developmental lineages. PRC2 is composed of the core subunit EZH1/2, EED, SUZ12, and RBBP4/ 7 together with a wide range of substoichiometric subunits defining distinct alternate protein complexes [22]. However, PRC2 catalytic activity relies only on the presence of the two mutually exclusive histone methyltransferases EZH1 or EZH2, associated with EED and SUZ12. In zebrafish, as the result of a genome duplication that occurred in the teleost lineage, the Suz12 subunit is encoded by two ohnologues, suz12a and suz12b. Then, eed is the sole zebrafish gene coding for a PRC2 subunit present in all alternate complexes. Consequently, since EED is required for EZH1/2 methyltransferase activity, it is expected that inactivation of the zebrafish eed gene will result in the loss of activity of all PRC2 complexes.

Using the TALEN technology, we generated an eed allele harboring a 14 bp deletion within the third exon. This deletion conducts to a frameshift within the coding sequence leading to the production of a putative protein lacking all the WD40 domains, predicted to be non-functional, and therefore likely producing an eed null allele. Heterozygous eed ${ }^{+/-}$ fish are viable, fertile, and do not present visible gross phenotypes. By opposition, $\mathrm{eed}^{-}$ homozygosity leads to larval death at around $12 \mathrm{dpf}$. This time point is similar to what was observed for zebrafish lacking the function of other PRC2 components, such as for ezh2 mutants [37,38] or suz12a; suz12b double-mutants [39], but contrasts to Eed knockout mouse phenotype [25]. While mouse embryos homozygous for the Eed mutation fail to gastrulate normally, eed embryonic expression is not required for the establishment of the zebrafish body plan. This relatively late lethality makes the zebrafish a compelling model to study PRC2 function during the development of various tissues without the requirement of conditional knockout strategies. It also reinforces the idea that PRC2 function plays little or no role in the implementation of developmental decisions but is mainly required to maintain these developmental instructions.

Zebrafish eed ${ }^{-/-}$mutants display various alterations of the digestive organs. These defects include a smaller pancreas at $5 \mathrm{dpf}$, hepatic steatosis characterized by an increase in lipids and macrovesicles in the liver, and the loss of maintenance of the intestine structures particularly marked at the level of the intestinal bulb. Studies in mice also pointed out the role of Eed in intestinal development [76]. Indeed, the conditional knockout of Eed in postnatal intestinal crypts decreases the stem cell pools, reduces the proliferation potential, increases the secretory cell differentiation, and results in smaller mouse intestines. Zebrafish larvae hatch with a yolk sac, which is depleted at 6-7 dpf. Then, after that time, their growth relies on external food uptake. If left unfed, the larvae will usually die of starvation at around $12 \mathrm{dpf}$ [77]. Thus, it is very likely that the defects of the digestive organs found 
in the eed ${ }^{-/-}$homozygous mutants account for their larval death at $12 \mathrm{dpf}$. Furthermore, the marked eed $\mathrm{d}^{-/-}$phenotype at the level of the digestive organs closely resembles the phenotype of the $e z h 2^{-/-}$homozygous mutants we have previously described [38]. These indistinguishable phenotypes exclude critical roles of Ezh1 and/or PRC2-independent Ezh2 functions in the development of the digestive organs, at least until $12 \mathrm{dpf}$.

Investigations on bulk histone modifications in eed-deficient larvae at $9 \mathrm{dpf}$ revealed a dramatic decrease in H3K27me2/3 marks, as expected. However, eed ${ }^{-1-}$ larvae retained some H3K27me2 and H3K27me3 residual methylation marks. We assume that the remaining H3K27me2/3 signals were deposited by the maternal PRC2 activity and retained in slowly dividing or quiescent cells. Maternal PRC2 contribution was previously demonstrated by showing that maternal-zygotic $M Z e z h 2^{-/-}$mutants display a much stronger

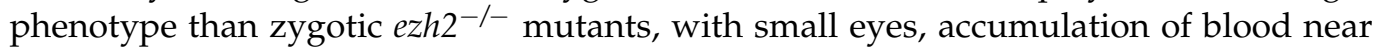
the yolk extension, stringy heart, heart edema, and absence of pectoral fins at $2 \mathrm{dpf}$ [37]. EZH1 and EZH2 are both able to deposit H3K27me1, but the role of PRC2 in the control of H3K27me1 monomethylation is still a matter of debate [20,58,78,79]. Studies using Eed and Suz12 knockout mouse ESC lines, as well as knockdown experiments in mouse ESCs, showed that the inhibition of PRC2 activity is responsible for a global loss of H3K27me2 and H3K27me3 levels, but at best for a partial reduction in H3K27me1 marks [24,80,81]. Our analysis in zebrafish revealed that H3K27me1 global levels are not significantly changed in eed ${ }^{-/-}$larvae indicating that in the absence of PRC2 function, H3K27 monomethylation is achieved by other histone methylation routes. It has been shown that the histone lysine methyltransferases G9a (EHMT2) and Glp (EHMT1), in addition to being potent H3K9 methyltransferases, are able to monomethylate H3K27 both in vitro and in mouse ESCs $[56,57,82]$. Thus, their zebrafish orthologs, Ehmt1a, Ehmt1b, and Ehmt2, appear as suitable candidates to account for monomethylation at H3K27 targets in the absence of PRC2 activity.

Polycomb repression is achieved by the combined action of both PRC2 and PRC1. While PRC2 methylates H3K27, PRC1 monoubiquitylates H2AK119. Multiple PRC1 subcomplexes have been shown to coexist in cells. These complexes are commonly referred to as canonical (cPRC1) or non-canonical (ncPRC1), based on their dependence on H3K27me3 recruitment to target loci [6,83]. We have shown that global H2AK119ub levels were unchanged in eed ${ }^{-/-}$larvae indicating H2K119 monoubiquitylation is maintained in the absence of PRC2 function, presumably thanks to ncPRC1 action. This situation is similar to what was observed in ESCs, where Ezh1/Ezh2 double knockout was reported to do not affect H2K119ub levels [58]. H2K119ub maintenance in $e^{-1-}$ mutants also explains the milder phenotype observed in eed-deficient fish when compared to $r n f 2^{-/-}$mutants. In zebrafish, Rnf2 is the only catalytic subunit common to all PRC1 subcomplexes [84]. Zebrafish deficient in $r n f 2$ gene function lack H2K119ub marks, display several defects including jaw malformation, pericardial edema, diminished blood circulation, absence of pectoral fins, severe craniofacial phenotype, and die at around $4-5 \mathrm{dpf}[85,86]$. However, our results contrast with another study using maternal-zygotic MZezh2 zebrafish mutants [87]. In this report, it was shown that loss of Ezh2 function from maternal and zygotic origins resulted in dramatic impairment of PRC1 recruitment at the chromatin and complete loss of H3K119ub marks. This observation highlighted the role of the PRC2 in the functional recruitment of $\mathrm{CPRC} 1$ complexes and led us to propose that in the absence of zygotic Eed function, maternal PRC2 activity is sufficient to deposit enough H3K27me3 marks allowing cPRC1 recruitment at early developmental stages. Then, at later stages, H2AK119ub marks are propagated and transmitted through cell generations in a PRC2-independent fashion via the action of ncPRC1 complexes. This hypothesis would explain why $r n f 2^{-1-}$ and MZezh2 ${ }^{-/-}$mutants display more severe phenotypes than ezh2 and eed homozygous zygotic mutants do. Furthermore, it has been demonstrated that ncPRC1 complexes are able to propagate $\mathrm{H} 2 \mathrm{AK} 119 \mathrm{ub}$ during cell division via their recruitment to the chromatin through the binding of the RYBP/YAF2 subunits to H2AK119ub marks [88]. 
Sequencing studies on pediatric high-grade gliomas, including glioblastoma multiformes (GBMs) and diffuse intrinsic pontine gliomas (DIPGs), identify recurrent somatic lysine to methionine substitutions at position $27(\mathrm{~K} 27 \mathrm{M})$ in histone $\mathrm{H} 3$. The $\mathrm{H} 3{ }^{\mathrm{K} 27 \mathrm{M}}$ mutation primarily occurs in $H 3 F 3 A(>70 \%)$, one of the two genes coding for the histone variant H3.3, with a lower frequency in HIST1H3B and HIST1H3C encoding H3.1, and more rarely in HIST2H3C coding for $\mathrm{H} 3.2$ [89-92]. The H3.3 ${ }^{\mathrm{K} 27 \mathrm{M}}$ mutated histone binds to EZH2 and inhibits the methyltransferase activity of the PRC2, leading to a dramatic decrease in global H3K27me3 marks and alterations in gene expression programs [93-97]. These changes in gene expression would sustain the undifferentiated phenotype of the tumor cells that contributes to the aggressiveness of the gliomas and to the dismal associated prognosis [94]. In addition to H3F3 $A^{K 27 M}$ mutations, DIPGs also contain genetic alterations targeting canonical signaling pathways, most frequently TP53 loss of function (about 60\%) and gain-of-function mutations or amplifications in platelet-derived growth factor receptor alpha (PDGFRA; about 40\%) [89,98], as well as numerous other mutations that might contribute to significant inter- and intratumoral DIPG heterogeneity and found at lower-frequencies [99]. However, the individual contribution of each of the different mutations, including $H 3 F 3 A^{K 27 M}$, in glioma genesis remains poorly understood. In this context, we took advantage of our eed-deficient zebrafish line to investigate the effects of PRC2 loss of activity on neuronal differentiation and proliferation. We found that in $e e d^{-/-}$larvae, expression of some stemness (bmi1a), as well as neuronal (neurod1) or glial (mag) precursor markers, is altered, indicating that neural differentiation is impaired in the absence of functional PRC2 activity. Interestingly, a number of human DIPGs have been shown positive for BMI1 expression, which then appears as a potential therapeutic target [100-102]. By contrast, our in situ hybridization experiments revealed that the pcna expression profile remained unchanged in the brain of $\mathrm{eed}^{-/-}$larvae suggesting that PRC2 loss of function and reduction in H3K27me3 marks do not affect the proliferation potential of neural cells. Thus, we propose that in DIPGs, the $H 3 F 3 A^{K 27 M}$ mutation is responsible for the maintenance of an undifferentiated state, whereas other mutations might contribute to proliferation.

Surprisingly, we also showed that while expressed ubiquitously in the brain of wildtype larvae, eed loss of function results in gene expression alterations in relatively thin and discrete areas of the brain. For instance, ectopic expression of phox $2 b b$ is specifically found in the retina, whereas neurod 1 expression is lost in a subset part of the hindbrain. Then, the effects of PRC2 loss of function appear strictly cell-specific and context-dependent, differentially affecting cell fates. These subtle changes in gene expression would indubitably escape to global transcriptomic analyses. Thus, our observations also outline the importance of performing whole-mount in situ hybridizations, but not only global transcriptomic analyses, for the characterization of zebrafish lines harboring mutations in polycomb group genes. In this context, it is worth emphasizing that the loss of eed function gives different phenotypes depending on the considered organ. It affects neuronal differentiation in specific brain regions, the development of the pancreas, the maintenance of the intestine wall structures, or the metabolism of lipids in the liver. This variation in effects and phenotypes might reflect the fact that Eed controls different gene expression programs in the different organs. It also reinforces the idea that a better deciphering of PRC2 function would rely on transcriptomic analyses at the single-cell level.

Cohen-Gibson syndrome (COGIS, OMIM \#617561) is an overgrowth disorder characterized by dysmorphic facial features, advanced bone age, skeletal abnormalities, associated with variable intellectual disability, and caused by de novo mutations in EED [30,103]. To date, COGIS (EED-related overgrowth) has been reported in eight individuals, with at least one patient showing hyperactivity [104]. Interestingly, our behavioral studies revealed that $e e d^{-1-}$ larvae also present a hyperactive phenotype, raising the possibility that the eed-deficient zebrafish line could constitute a pertinent model to study the neurological defects leading to behavioral disabilities in COGIS. 
Supplementary Materials: The following are available online at https://www.mdpi.com/article/10 .3390/cells10113142/s1, Figure S1: Uncropped RT-PRC gels used in Figure 1; Figure S2: Uncropped Western blot used in Figure 3.

Author Contributions: Conceptualization and supervision: P.-O.A.; Methodology and data collection: L.R., P.V., S.H., J.C. and P.-O.A.; Formal Analysis: L.R., P.V., S.H., R.-A.T., E.A., I.V.S., X.L.B., and P.-O.A.; Resources and funding acquisition: R.-A.T., E.A., I.V.S., X.L.B. and P.-O.A.; Original draft preparation: P.-O.A.; Revision of the manuscript: L.R., P.V., R.-A.T., I.V.S. and X.L.B. All authors have read and agreed to the published version of the manuscript.

Funding: This work was supported by the CNRS, Inserm, the University of Lille, the Ligue Contre le Cancer-Comité du Pas-de-Calais and the GIP Cancéropôle Nord-Ouest. This study was supported by a grant from Contrat de Plan Etat-Région CPER Cancer 2015-2020.

Institutional Review Board Statement: Zebrafish were maintained in compliance with the French and European Union guidelines (Directive 2010/63/EU of the European Parliament and of the Council of 22 September 2010 on the protection of animals used for scientific purposes) and the experimental procedures on zebrafish were reviewed and approved by the local Ethics Committee, CEEA 75 Nord Pas-de-Calais, and the French Ministry of Higher Education and Research (APAFiS approval number 13527-2018011722529804_v3).

Informed Consent Statement: Not applicable.

Data Availability Statement: All relevant data are within the manuscript.

Acknowledgments: We are grateful to Barbara Dupret, Anaïs Chapart, Aurélie Bary, Amélie Boudelle, and Adeline Duquesnoy for technical assistance. S.H. was recipient of a visiting research scholarship from the Ministry of Science, Research and Technology of the Islamic Republic of Iran.

Conflicts of Interest: The authors declare no conflict of interest. The funders had no role in the design of the study; in the collection, analyses, or interpretation of data; in the writing of the manuscript, or in the decision to publish the results.

\section{References}

1. Di Croce, L.; Helin, K. Transcriptional regulation by Polycomb group proteins. Nat. Struct. Mol. Biol. 2013, 20, 1147-1155. [CrossRef] [PubMed]

2. Sauvageau, M.; Sauvageau, G. Polycomb group proteins: Multi-faceted regulators of somatic stem cells and cancer. Cell Stem Cell 2010, 7, 299-313. [CrossRef]

3. Surface, L.E.; Thornton, S.R.; Boyer, L.A. Polycomb group proteins set the stage for early lineage commitment. Cell Stem Cell 2010, 7, 288-298. [CrossRef]

4. Geng, Z.; Gao, Z. Mammalian PRC1 Complexes: Compositional Complexity and Diverse Molecular Mechanisms. Int. J. Mol. Sci. 2020, 21, 8594. [CrossRef]

5. Glancy, E.; Ciferri, C.; Bracken, A.P. Structural basis for PRC2 engagement with chromatin. Curr. Opin. Struct. Biol. 2021, 67, 135-144. [CrossRef] [PubMed]

6. Piunti, A.; Shilatifard, A. The roles of Polycomb repressive complexes in mammalian development and cancer. Nat. Rev. Mol. Cell Biol. 2021, 22, 326-345. [CrossRef]

7. Cao, R.; Wang, L.; Wang, H.; Xia, L.; Erdjument-Bromage, H.; Tempst, P.; Jones, R.S.; Zhang, Y. Role of histone H3 lysine 27 methylation in Polycomb-group silencing. Science 2002, 298, 1039-1043. [CrossRef]

8. Kuzmichev, A.; Nishioka, K.; Erdjument-Bromage, H.; Tempst, P.; Reinberg, D. Histone methyltransferase activity associated with a human multiprotein complex containing the Enhancer of Zeste protein. Genes Dev. 2002, 16, 2893-2905. [CrossRef]

9. Müller, J.; Hart, C.M.; Francis, N.J.; Vargas, M.L.; Sengupta, A.; Wild, B.; Miller, E.L.; O'Connor, M.B.; Kingston, R.E.; Simon, J.A. Histone methyltransferase activity of a Drosophila Polycomb group repressor complex. Cell 2002, 111, 197-208. [CrossRef]

10. Wang, H.; Wang, L.; Erdjument-Bromage, H.; Vidal, M.; Tempst, P.; Jones, R.S.; Zhang, Y. Role of histone H2A ubiquitination in Polycomb silencing. Nature 2004, 431, 873-878. [CrossRef]

11. de Napoles, M.; Mermoud, J.E.; Wakao, R.; Tang, Y.A.; Endoh, M.; Appanah, R.; Nesterova, T.B.; Silva, J.; Otte, A.P.; Vidal, M.; et al. Polycomb group proteins Ring1A/B link ubiquitylation of histone H2A to heritable gene silencing and X inactivation. Dev. Cell 2004, 7, 663-676. [CrossRef]

12. Boyer, L.A.; Plath, K.; Zeitlinger, J.; Brambrink, T.; Medeiros, L.A.; Lee, T.I.; Levine, S.S.; Wernig, M.; Tajonar, A.; Ray, M.K.; et al. Polycomb complexes repress developmental regulators in murine embryonic stem cells. Nature 2006, 441, 349-353. [CrossRef] [PubMed]

13. Azuara, V.; Perry, P.; Sauer, S.; Spivakov, M.; Jørgensen, H.F.; John, R.M.; Gouti, M.; Casanova, M.; Warnes, G.; Merkenschlager, M.; et al. Chromatin signatures of pluripotent cell lines. Nat. Cell Biol. 2006, 8, 532-538. [CrossRef] 
14. Bernstein, B.E.; Mikkelsen, T.S.; Xie, X.; Kamal, M.; Huebert, D.J.; Cuff, J.; Fry, B.; Meissner, A.; Wernig, M.; Plath, K.; et al. A bivalent chromatin structure marks key developmental genes in embryonic stem cells. Cell 2006, 125, 315-326. [CrossRef]

15. Bracken, A.P.; Dietrich, N.; Pasini, D.; Hansen, K.H.; Helin, K. Genome-wide mapping of Polycomb target genes unravels their roles in cell fate transitions. Genes Dev. 2006, 20, 1123-1136. [CrossRef] [PubMed]

16. Lee, T.I.; Jenner, R.G.; Boyer, L.A.; Guenther, M.G.; Levine, S.S.; Kumar, R.M.; Chevalier, B.; Johnstone, S.E.; Cole, M.F.; Isono, K.; et al. Control of developmental regulators by Polycomb in human embryonic stem cells. Cell 2006, 125, 301-313. [CrossRef] [PubMed]

17. Mikkelsen, T.S.; Ku, M.; Jaffe, D.B.; Issac, B.; Lieberman, E.; Giannoukos, G.; Alvarez, P.; Brockman, W.; Kim, T.K.; Koche, R.P.; et al. Genome-wide maps of chromatin state in pluripotent and lineage-committed cells. Nature 2007, 448, 553-560. [CrossRef]

18. Pan, G.; Tian, S.; Nie, J.; Yang, C.; Ruotti, V.; Wei, H.; Jonsdottir, G.A.; Stewart, R.; Thomson, J.A. Whole-genome analysis of histone H3 lysine 4 and lysine 27 methylation in human embryonic stem cells. Cell Stem Cell 2007, 1, 299-312. [CrossRef]

19. Zhao, X.D.; Han, X.; Chew, J.L.; Liu, J.; Chiu, K.P.; Choo, A.; Orlov, Y.L.; Sung, W.K.; Shahab, A.; Kuznetsov, V.A.; et al. Wholegenome mapping of histone $\mathrm{H} 3 \mathrm{Lys} 4$ and 27 trimethylations reveals distinct genomic compartments in human embryonic stem cells. Cell Stem Cell 2007, 1, 286-298. [CrossRef]

20. Margueron, R.; Li, G.; Sarma, K.; Blais, A.; Zavadil, J.; Woodcock, C.L.; Dynlacht, B.D.; Reinberg, D. Ezh1 and Ezh2 maintain repressive chromatin through different mechanisms. Mol. Cell 2008, 32, 503-518. [CrossRef]

21. Kouznetsova, V.L.; Tchekanov, A.; Li, X.; Yan, X.; Tsigelny, I.F. Polycomb repressive 2 complex-Molecular mechanisms of function. Protein Sci. 2019, 28, 1387-1399. [CrossRef]

22. Van Mierlo, G.; Veenstra, G.J.C.; Vermeulen, M.; Marks, H. The Complexity of PRC2 Subcomplexes. Trends Cell Biol. 2019, 29, 660-671. [CrossRef]

23. Chammas, P.; Mocavini, I.; Di Croce, L. Engaging chromatin: PRC2 structure meets function. Br. J. Cancer 2020, 122, 315-328. [CrossRef]

24. Pasini, D.; Bracken, A.P.; Jensen, M.R.; Lazzerini Denchi, E.; Helin, K. Suz12 is essential for mouse development and for EZH2 histone methyltransferase activity. EMBO J. 2004, 23, 4061-4071. [CrossRef]

25. Faust, C.; Schumacher, A.; Holdener, B.; Magnuson, T. The eed mutation disrupts anterior mesoderm production in mice. Development 1995, 121, 273-285. [CrossRef]

26. Ueda, T.; Sanada, M.; Matsui, H.; Yamasaki, N.; Honda, Z.I.; Shih, L.Y.; Mori, H.; Inaba, T.; Ogawa, S.; Honda, H. EED mutants impair polycomb repressive complex 2 in myelodysplastic syndrome and related neoplasms. Leukemia 2012, 26, 2557-2560. [CrossRef] [PubMed]

27. De Raedt, T.; Beert, E.; Pasmant, E.; Luscan, A.; Brems, H.; Ortonne, N.; Helin, K.; Hornick, J.L.; Mautner, V.; Kehrer-Sawatzki, H.; et al. PRC2 loss amplifies Ras-driven transcription and confers sensitivity to BRD4-based therapies. Nature 2014, 514, $247-251$. [CrossRef] [PubMed]

28. Lee, W.; Teckie, S.; Wiesner, T.; Ran, L.; Prieto Granada, C.N.; Lin, M.; Zhu, S.; Cao, Z.; Liang, Y.; Sboner, A. PRC2 is recurrently inactivated through EED or SUZ12 loss in malignant peripheral nerve sheath tumors. Nat. Genet. 2014, 46, 1227-1232. [CrossRef] [PubMed]

29. Erokhin, M.; Chetverina, O.; Győrffy, B.; Tatarskiy, V.V.; Mogila, V.; Shtil, A.A.; Roninson, I.B.; Moreaux, J.; Georgiev, P.; Cavalli, G.; et al. Clinical Correlations of Polycomb Repressive Complex 2 in Different Tumor Types. Cancers 2021, 13, 3155. [CrossRef]

30. Cohen, A.S.; Tuysuz, B.; Shen, Y.; Bhalla, S.K.; Jones, S.J.; Gibson, W.T. A novel mutation in EED associated with overgrowth. J. Hum. Genet. 2015, 60, 339-342. [CrossRef] [PubMed]

31. Imagawa, E.; Higashimoto, K.; Sakai, Y.; Numakura, C.; Okamoto, N.; Matsunaga, S.; Ryo, A.; Sato, Y.; Sanefuji, M.; Ihara, K.; et al. Mutations in genes encoding polycomb repressive complex 2 subunits cause Weaver syndrome. Hum. Mutat. 2017, 38, 637-648. [CrossRef]

32. Cooney, E.; Bi, W.; Schlesinger, A.E.; Vinson, S.; Potocki, L. Novel EED mutation in patient with Weaver syndrome. Am. J. Med. Genet. A 2017, 173, 541-545. [CrossRef]

33. Griffiths, S.; Loveday, C.; Zachariou, A.; Behan, L.A.; Chandler, K.; Cole, T.; D’Arrigo, S.; Dieckmann, A.; Foster, A.; Gibney, J.; et al. EED and EZH2 constitutive variants: A study to expand the Cohen-Gibson syndrome phenotype and contrast it with Weaver syndrome. Am. J. Med. Genet. A 2019, 179, 588-594. [CrossRef]

34. Spellicy, C.J.; Peng, Y.; Olewiler, L.; Cathey, S.S.; Rogers, R.C.; Bartholomew, D.; Johnson, J.; Alexov, E.; Lee, J.A.; Friez, M.J.; et al. Three additional patients with EED-associated overgrowth: Potential mutation hotspots identified? J. Hum. Genet. 2019, 64, 561-572. [CrossRef] [PubMed]

35. Völkel, P.; Bary, A.; Raby, L.; Chapart, A.; Dupret, B.; Le Bourhis, X.; Angrand, P.O. Ezh1 arises from Ezh2 gene duplication but its function is not required for zebrafish development. Sci. Rep. 2019, 9, 4319. [CrossRef]

36. Soto, R.A.; Najia, M.A.T.; Hachimi, M.; Frame, J.M.; Yette, G.A.; Lummertz da Rocha, E.; Stankunas, K.; Daley, G.Q.; North, T.E. Sequential regulation of hemogenic fate and hematopoietic stem and progenitor cell formation from arterial endothelium by Ezh1/2. Stem Cell Rep. 2021, 16, 1718-1734. [CrossRef]

37. San, B.; Chrispijn, N.D.; Wittkopp, N.; van Heeringen, S.J.; Lagendijk, A.K.; Aben, M.; Bakkers, J.; Ketting, R.F.; Kamminga, L.M. Normal formation of a vertebrate body plan and loss of tissue maintenance in the absence of ezh2. Sci. Rep. 2016, 6, 24658. [CrossRef] [PubMed] 
38. Dupret, B.; Völkel, P.; Vennin, C.; Toillon, R.A.; Le Bourhis, X.; Angrand, P.O. The histone lysine methyltransferase Ezh2 is required for maintenance of the intestine integrity and for caudal fin regeneration in zebrafish. Biochim. Biophys. Acta Gene Regul. Mech. 2017, 1860, 1079-1093. [CrossRef]

39. Oppel, F.; Ki, D.H.; Zimmerman, M.W.; Ross, K.N.; Tao, T.; Shi, H.; He, S.; Aster, J.C.; Look, A.T. suz12 inactivation in p53- and nf1-deficient zebrafish accelerates the onset of malignant peripheral nerve sheath tumors and expands the spectrum of tumor types. Dis. Model Mech. 2020, 13, dmm042341. [CrossRef] [PubMed]

40. Maître, J.L.; Berthoumieux, H.; Krens, S.F.; Salbreux, G.; Jülicher, F.; Paluch, E.; Heisenberg, C.P. Adhesion functions in cell sorting by mechanically coupling the cortices of adhering cells. Science 2012, 338, 253-256. [CrossRef]

41. Kimmel, C.B.; Ballard, W.W.; Kimmel, S.R.; Ullmann, B.; Schilling, T.F. Stages of embryonic development of the zebrafish. Dev. Dyn. 1995, 203, 253-310. [CrossRef] [PubMed]

42. Dupret, B.; Völkel, P.; Le Bourhis, X.; Angrand, P.O. The Polycomb Group Protein Pcgf1 Is Dispensable in Zebrafish but Involved in Early Growth and Aging. PLoS ONE 2016, 11, e0158700. [CrossRef]

43. Doyle, E.L.; Booher, N.J.; Standage, D.S.; Voytas, D.F.; Brendel, V.P.; Vandyk, J.K.; Bogdanove, A.J. TAL Effector-Nucleotide Targeter (TALE-NT) 2.0: Tools for TAL effector design and target prediction. Nucleic Acids Res. 2012, 40, W117-W122. [CrossRef] [PubMed]

44. Cermak, T.; Doyle, E.L.; Christian, M.; Wang, L.; Zhang, Y.; Schmidt, C.; Baller, J.A.; Somia, N.V.; Bogdanove, A.J.; Voytas, D.F. Efficient design and assembly of custom TALEN and other TAL effector-based constructs for DNA targeting. Nucleic Acids Res. 2011, 39, e82. [CrossRef] [PubMed]

45. Dahlem, T.J.; Hoshijima, K.; Jurynec, M.J.; Gunther, D.; Starker, C.G.; Locke, A.S.; Weis, A.M.; Voytas, D.F.; Grunwald, D.J. Simple methods for generating and detecting locus-specific mutations induced with TALENs in the zebrafish genome. PLoS Genet. 2012, 8, e1002861. [CrossRef]

46. Dupret, B.; Völkel, P.; Follet, P.; Le Bourhis, X.; Angrand, P.O. Combining genotypic and phenotypic analyses on single mutant zebrafish larvae. MethodsX 2018, 5, 244-256. [CrossRef]

47. Dambroise, E.; Monnier, L.; Ruisheng, L.; Aguilaniu, H.; Joly, J.S.; Tricoire, H.; Rera, M. Two phases of aging separated by the Smurf transition as a public path to death. Sci. Rep. 2016, 6, 23523. [CrossRef] [PubMed]

48. Parichy, D.M.; Elizondo, M.R.; Mills, M.G.; Gordon, T.N.; Engeszer, R.E. Normal table of postembryonic zebrafish development: Staging by externally visible anatomy of the living fish. Dev. Dyn. 2009, 238, 2975-3015. [CrossRef]

49. Thisse, C.; Thisse, B. High-resolution in situ hybridization to whole-mount zebrafish embryos. Nat. Protoc. 2008, 3, 59-69. [CrossRef]

50. Raby, L.; Völkel, P.; Le Bourhis, X.; Angrand, P.O. The Polycomb Orthologues in Teleost Fishes and Their Expression in the Zebrafish Model. Genes 2020, 11, 362. [CrossRef]

51. Han, Z.; Xing, X.; Hu, M.; Zhang, Y.; Liu, P.; Chai, J. Structural basis of EZH2 recognition by EED. Structure 2007, 15, 1306-1315. [CrossRef]

52. Pelegri, F. Maternal factors in zebrafish development. Dev. Dyn. 2003, 228, 535-554. [CrossRef]

53. Dosch, R.; Wagner, D.S.; Mintzer, K.A.; Runke, G.; Wiemelt, A.P.; Mullins, M.C. Maternal control of vertebrate development before the midblastula transition: Mutants from the zebrafish I. Dev. Cell 2004, 6, 771-780. [CrossRef] [PubMed]

54. Chrispijn, N.D.; Andralojc, K.M.; Castenmiller, C.; Kamminga, L.M. Gene expression profile of a selection of Polycomb Group genes during zebrafish embryonic and germ line development. PLoS ONE 2018, 13, e0200316. [CrossRef] [PubMed]

55. White, R.J.; Collins, J.E.; Sealy, I.M.; Wali, N.; Dooley, C.M.; Digby, Z.; Stemple, D.L.; Murphy, D.N.; Billis, K.; Hourlier, T.; et al. A high-resolution mRNA expression time course of embryonic development in zebrafish. eLife 2017, 6, e30860. [CrossRef] [PubMed]

56. Tachibana, M.; Ueda, J.; Fukuda, M.; Takeda, N.; Ohta, T.; Iwanari, H.; Sakihama, T.; Kodama, T.; Hamakubo, T.; Shinkai, Y. Histone methyltransferases G9a and GLP form heteromeric complexes and are both crucial for methylation of euchromatin at H3-K9. Genes Dev. 2005, 19, 815-826. [CrossRef] [PubMed]

57. Wu, H.; Chen, X.; Xiong, J.; Li, Y.; Li, H.; Ding, X.; Liu, S.; Chen, S.; Gao, S.; Zhu, B. Histone methyltransferase G9a contributes to H3K27 methylation in vivo. Cell Res. 2011, 21, 365-367. [CrossRef]

58. Lavarone, E.; Barbieri, C.M.; Pasini, D. Dissecting the role of H3K27 acetylation and methylation in PRC2 mediated control of cellular identity. Nat. Commun. 2019, 10, 1679. [CrossRef]

59. Piunti, A.; Hashizume, R.; Morgan, M.A.; Bartom, E.T.; Horbinski, C.M.; Marshall, S.A.; Rendleman, E.J.; Ma, Q.; Takahashi, Y.H.; Woodfin, A.R.; et al. Therapeutic targeting of polycomb and BET bromodomain proteins in diffuse intrinsic pontine gliomas. Nat. Med. 2017, 23, 493-500. [CrossRef]

60. Gao, Z.; Zhang, J.; Bonasio, R.; Strino, F.; Sawai, A.; Parisi, F.; Kluger, Y.; Reinberg, D. PCGF homologs, CBX proteins, and RYBP define functionally distinct PRC1 family complexes. Mol. Cell 2012, 45, 344-356. [CrossRef]

61. Tavares, L.; Dimitrova, E.; Oxley, D.; Webster, J.; Poot, R.; Demmers, J.; Bezstarosti, K.; Taylor, S.; Ura, H.; Koide, H.; et al. RYBP-PRC1 complexes mediate H2A ubiquitylation at polycomb target sites independently of PRC2 and H3K27me3. Cell 2012, 148, 664-678. [CrossRef]

62. Morey, L.; Aloia, L.; Cozzuto, L.; Benitah, S.A.; Di Croce, L. RYBP and Cbx7 define specific biological functions of polycomb complexes in mouse embryonic stem cells. Cell Rep. 2013, 3, 60-69. [CrossRef]

63. San, B.; Aben, M.; Elurbe, D.M.; Voeltzke, K.; Den Broeder, M.J.; Rougeot, J.; Legler, J.; Kamminga, L.M. Genetic and Epigenetic Regulation of Zebrafish Intestinal Development. Epigenomes 2018, 2, 19. [CrossRef] 
64. Behrndt, M.; Salbreux, G.; Campinho, P.; Hauschild, R.; Oswald, F.; Roensch, J.; Grill, S.W.; Heisenberg, C.P. Forces driving epithelial spreading in zebrafish gastrulation. Science 2012, 338, 257-260. [CrossRef]

65. Araya, C.; Häkkinen, H.M.; Carcamo, L.; Cerda, M.; Savy, T.; Rookyard, C.; Peyriéras, N.; Clarke, J.D.W. Cdh2 coordinates Myosin-II dependent internalisation of the zebrafish neural plate. Sci. Rep. 2019, 9, 1835. [CrossRef]

66. Dai, W.; Wang, K.; Zheng, X.; Chen, X.; Zhang, W.; Zhang, Y.; Hou, J.; Liu, L. High fat plus high cholesterol diet lead to hepatic steatosis in zebrafish larvae: A novel model for screening anti-hepatic steatosis drugs. Nutr. Metab. 2015, 12, 42. [CrossRef] [PubMed]

67. Chen, B.; Zheng, Y.M.; Zhang, J.P. Comparative Study of Different Diets-Induced NAFLD Models of Zebrafish. Front. Endocrinol. 2018, 9, 366. [CrossRef] [PubMed]

68. Howarth, D.L.; Lindtner, C.; Vacaru, A.M.; Sachidanandam, R.; Tsedensodnom, O.; Vasilkova, T.; Buettner, C.; Sadler, K.C. Activating transcription factor 6 is necessary and sufficient for alcoholic fatty liver disease in zebrafish. PLoS Genet. 2014, 10, e1004335. [CrossRef] [PubMed]

69. Yin, G.; Cao, L.; Du, J.; Jia, R.; Kitazawa, T.; Kubota, A.; Teraoka, H. Dexamethasone-induced hepatomegaly and steatosis in larval zebrafish. J. Toxicol. Sci. 2017, 42, 455-459. [CrossRef]

70. Katoch, S.; Patial, V. Zebrafish: An emerging model system to study liver diseases and related drug discovery. J. Appl. Toxicol. 2021, 41, 33-51. [CrossRef]

71. den Broeder, M.J.; Ballangby, J.; Kamminga, L.M.; Aleström, P.; Legler, J.; Lindeman, L.C.; Kamstra, J.H. Inhibition of methyltransferase activity of enhancer of zeste 2 leads to enhanced lipid accumulation and altered chromatin status in zebrafish. Epigenet. Chromatin 2020, 13, 5. [CrossRef]

72. Alunni, A.; Hermel, J.M.; Heuzé, A.; Bourrat, F.; Jamen, F.; Joly, J.S. Evidence for neural stem cells in the medaka optic tectum proliferation zones. Dev. Neurobiol. 2010, 70, 693-713. [CrossRef] [PubMed]

73. MacPhail, R.C.; Brooks, J.; Hunter, D.L.; Padnos, B.; Irons, T.D.; Padilla, S. Locomotion in larval zebrafish: Influence of time of day, lighting and ethanol. Neurotoxicology 2009, 30, 52-58. [CrossRef]

74. Schnörr, S.J.; Steenbergen, P.J.; Richardson, M.K.; Champagne, D.L. Measuring thigmotaxis in larval zebrafish. Behav. Brain Res. 2012, 228, 367-374. [CrossRef] [PubMed]

75. Douek, A.M.; Amiri Khabooshan, M.; Henry, J.; Stamatis, S.A.; Kreuder, F.; Ramm, G.; Änkö, M.L.; Wlodkowic, D.; Kaslin, J. An Engineered sgsh Mutant Zebrafish Recapitulates Molecular and Behavioural Pathobiology of Sanfilippo Syndrome A/MPS IIIA. Int. J. Mol. Sci. 2021, 22, 5948. [CrossRef] [PubMed]

76. Koppens, M.A.; Bounova, G.; Gargiulo, G.; Tanger, E.; Janssen, H.; Cornelissen-Steijger, P.; Blom, M.; Song, J.Y.; Wessels, L.F.; van Lohuizen, M. Deletion of Polycomb Repressive Complex 2 from Mouse Intestine Causes Loss of Stem Cells. Gastroenterology 2016, 151, 684-697. [CrossRef]

77. Lucore, E.C.; Connaughton, V.P. Observational learning and irreversible starvation in first-feeding zebrafish larvae: Is it okay to copy from your friends? Zoology 2021, 145, 125896. [CrossRef]

78. Shen, X.; Liu, Y.; Hsu, Y.J.; Fujiwara, Y.; Kim, J.; Mao, X.; Yuan, G.C.; Orkin, S.H. EZH1 mediates methylation on histone H3 lysine 27 and complements EZH2 in maintaining stem cell identity and executing pluripotency. Mol. Cell 2008, 32, 491-502. [CrossRef]

79. Lee, C.H.; Holder, M.; Grau, D.; Saldaña-Meyer, R.; Yu, J.R.; Ganai, R.A.; Zhang, J.; Wang, M.; LeRoy, G.; Dobenecker, M.W.; et al. Distinct Stimulatory Mechanisms Regulate the Catalytic Activity of Polycomb Repressive Complex 2. Mol. Cell 2018, 70, 435-448. [CrossRef]

80. Cao, R.; Zhang, Y. SUZ12 is required for both the histone methyltransferase activity and the silencing function of the EEDEZH2 complex. Mol. Cell 2004, 15, 57-67. [CrossRef]

81. Ferrari, K.J.; Scelfo, A.; Jammula, S.; Cuomo, A.; Barozzi, I.; Stützer, A.; Fischle, W.; Bonaldi, T.; Pasini, D. Polycomb-dependent H3K27me1 and H3K27me2 regulate active transcription and enhancer fidelity. Mol. Cell 2014, 53, 49-62. [CrossRef]

82. Tachibana, M.; Sugimoto, K.; Fukushima, T.; Shinkai, Y. Set domain-containing protein, G9a, is a novel lysine-preferring mammalian histone methyltransferase with hyperactivity and specific selectivity to lysines 9 and 27 of histone H3. J. Biol. Chem. 2001, 276, 25309-25317. [CrossRef] [PubMed]

83. Aranda, S.; Mas, G.; Di Croce, L. Regulation of gene transcription by Polycomb proteins. Sci. Adv. 2015, 1, e1500737. [CrossRef]

84. Le Faou, P.; Völkel, P.; Angrand, P.O. The zebrafish genes encoding the Polycomb repressive complex (PRC) 1. Gene 2011, 475, 10-21. [CrossRef]

85. Van der Velden, Y.U.; Wang, L.; van Lohuizen, M.; Haramis, A.P. The Polycomb group protein Ring1b is essential for pectoral fin development. Development 2012, 139, 2210-2220. [CrossRef] [PubMed]

86. Van der Velden, Y.U.; Wang, L.; Querol Cano, L.; Haramis, A.P. The polycomb group protein ring1b/rnf2 is specifically required for craniofacial development. PLoS ONE 2013, 8, e73997. [CrossRef]

87. Rougeot, J.; Chrispijn, N.D.; Aben, M.; Elurbe, D.M.; Andralojc, K.M.; Murphy, P.J.; Jansen, P.W.T.C.; Vermeulen, M.; Cairns, B.R.; Kamminga, L.M. Maintenance of spatial gene expression by Polycomb-mediated repression after formation of a vertebrate body plan. Development 2019, 146, dev178590. [CrossRef]

88. Zhao, J.; Wang, M.; Chang, L.; Yu, J.; Song, A.; Liu, C.; Huang, W.; Zhang, T.; Wu, X.; Shen, X.; et al. RYBP/YAF2-PRC1 complexes and histone H1-dependent chromatin compaction mediate propagation of H2AK119ub1 during cell division. Nat. Cell Biol. 2020, 22, 439-452. [CrossRef] [PubMed] 
89. Schwartzentruber, J.; Korshunov, A.; Liu, X.Y.; Jones, D.T.; Pfaff, E.; Jacob, K.; Sturm, D.; Fontebasso, A.M.; Quang, D.A.; Tönjes, M.; et al. Driver mutations in histone H3.3 and chromatin remodelling genes in paediatric glioblastoma. Nature 2012, 482, 226-231. [CrossRef]

90. Wu, G.; Broniscer, A.; McEachron, T.A.; Lu, C.; Paugh, B.S.; Becksfort, J.; Qu, C.; Ding, L.; Huether, R.; Parker, M.; et al. Somatic histone $\mathrm{H} 3$ alterations in pediatric diffuse intrinsic pontine gliomas and non-brainstem glioblastomas. Nat. Genet. 2012, 44, 251-253. [CrossRef]

91. Fontebasso, A.M.; Papillon-Cavanagh, S.; Schwartzentruber, J.; Nikbakht, H.; Gerges, N.; Fiset, P.O.; Bechet, D.; Faury, D.; De Jay, N.; Ramkissoon, L.A.; et al. Recurrent somatic mutations in ACVR1 in pediatric midline high-grade astrocytoma. Nat. Genet. 2014, 46, 462-466. [CrossRef]

92. Castel, D.; Philippe, C.; Calmon, R.; Le Dret, L.; Truffaux, N.; Boddaert, N.; Pagès, M.; Taylor, K.R.; Saulnier, P.; Lacroix, L.; et al. Histone H3F3A and HIST1H3B K27M mutations define two subgroups of diffuse intrinsic pontine gliomas with different prognosis and phenotypes. Acta Neuropathol. 2015, 130, 815-827. [CrossRef]

93. Bender, S.; Tang, Y.; Lindroth, A.M.; Hovestadt, V.; Jones, D.T.; Kool, M.; Zapatka, M.; Northcott, P.A.; Sturm, D.; Wang, W.; et al. Reduced H3K27me3 and DNA hypomethylation are major drivers of gene expression in K27M mutant pediatric high-grade gliomas. Cancer Cell 2013, 24, 660-672. [CrossRef]

94. Chan, K.M.; Fang, D.; Gan, H.; Hashizume, R.; Yu, C.; Schroeder, M.; Gupta, N.; Mueller, S.; James, C.D.; Jenkins, R.; et al. The histone H3.3K27M mutation in pediatric glioma reprograms H3K27 methylation and gene expression. Genes Dev. 2013, 27, 985-990. [CrossRef] [PubMed]

95. Herz, H.M.; Morgan, M.; Gao, X.; Jackson, J.; Rickels, R.; Swanson, S.K.; Florens, L.; Washburn, M.P.; Eissenberg, J.C.; Shilatifard, A. Histone H3 lysine-to-methionine mutants as a paradigm to study chromatin signaling. Science 2014, 345, 1065-1070. [CrossRef]

96. Lewis, P.W.; Müller, M.M.; Koletsky, M.S.; Cordero, F.; Lin, S.; Banaszynski, L.A.; Garcia, B.A.; Muir, T.W.; Becher, O.J.; Allis, C.D. Inhibition of PRC2 activity by a gain-of-function H3 mutation found in pediatric glioblastoma. Science 2013, 340, 857-861. [CrossRef] [PubMed]

97. Venneti, S.; Garimella, M.T.; Sullivan, L.M.; Martinez, D.; Huse, J.T.; Heguy, A.; Santi, M.; Thompson, C.B.; Judkins, A.R. Evaluation of histone 3 lysine 27 trimethylation (H3K27me3) and enhancer of Zest 2 (EZH2) in pediatric glial and glioneuronal tumors shows decreased H3K27me3 in H3F3A K27M mutant glioblastomas. Brain Pathol. 2013, 23, 558-564. [CrossRef]

98. Khuong-Quang, D.A.; Buczkowicz, P.; Rakopoulos, P.; Liu, X.Y.; Fontebasso, A.M.; Bouffet, E.; Bartels, U.; Albrecht, S.; Schwartzentruber, J.; Letourneau, L.; et al. K27M mutation in histone H3.3 defines clinically and biologically distinct subgroups of pediatric diffuse intrinsic pontine gliomas. Acta Neuropathol. 2012, 124, 439-447. [CrossRef] [PubMed]

99. Mackay, A.; Burford, A.; Carvalho, D.; Izquierdo, E.; Fazal-Salom, J.; Taylor, K.R.; Bjerke, L.; Clarke, M.; Vinci, M.; Nandhabalan, M.; et al. Integrated Molecular Meta-Analysis of 1,000 Pediatric High-Grade and Diffuse Intrinsic Pontine Glioma. Cancer Cell 2017, 32, 520-537. [CrossRef]

100. Ballester, L.Y.; Wang, Z.; Shandilya, S.; Miettinen, M.; Burger, P.C.; Eberhart, C.G.; Rodriguez, F.J.; Raabe, E.; Nazarian, J.; Warren, K.; et al. Morphologic characteristics and immunohistochemical profile of diffuse intrinsic pontine gliomas. Am. J. Surg. Pathol. 2013, 37, 1357-1364. [CrossRef]

101. Kumar, S.S.; Sengupta, S.; Lee, K.; Hura, N.; Fuller, C.; DeWire, M.; Stevenson, C.B.; Fouladi, M.; Drissi, R. BMI-1 is a potential therapeutic target in diffuse intrinsic pontine glioma. Oncotarget 2017, 8, 62962-62975. [CrossRef] [PubMed]

102. Balakrishnan, I.; Danis, E.; Pierce, A.; Madhavan, K.; Wang, D.; Dahl, N.; Sanford, B.; Birks, D.K.; Davidson, N.; Metselaar, D.S.; et al. Senescence Induced by BMI1 Inhibition Is a Therapeutic Vulnerability in H3K27M-Mutant DIPG. Cell Rep. 2020, $33,108286$. [CrossRef] [PubMed]

103. Cohen, A.S.; Gibson, W.T. EED-associated overgrowth in a second male patient. J. Hum. Genet. 2016, 61, 831-834. [CrossRef] [PubMed]

104. Sequerra Amram Cohen, A.; Gibson, W.T. EED-Related Overgrowth. In GeneReviews ${ }^{\circledR}$ [Internet]; Adam, M.P., Ardinger, H.H., Pagon, R.A., Wallace, S.E., Bean, L.J.H., Mirzaa, G., Amemiya, A., Eds.; University of Washington: Seattle, WA, USA, 2019; pp. 1993-2021. 